NASA/TM-2013-217821

\title{
Aircraft Turbine Engine Control Research at NASA Glenn Research Center
}

Sanjay Garg

Glenn Research Center, Cleveland, Ohio 


\section{NASA STI Program . . . in Profile}

Since its founding, NASA has been dedicated to the advancement of aeronautics and space science. The NASA Scientific and Technical Information (STI) program plays a key part in helping NASA maintain this important role.

The NASA STI Program operates under the auspices of the Agency Chief Information Officer. It collects, organizes, provides for archiving, and disseminates NASA's STI. The NASA STI program provides access to the NASA Aeronautics and Space Database and its public interface, the NASA Technical Reports Server, thus providing one of the largest collections of aeronautical and space science STI in the world. Results are published in both non-NASA channels and by NASA in the NASA STI Report Series, which includes the following report types:

- TECHNICAL PUBLICATION. Reports of completed research or a major significant phase of research that present the results of NASA programs and include extensive data or theoretical analysis. Includes compilations of significant scientific and technical data and information deemed to be of continuing reference value. NASA counterpart of peer-reviewed formal professional papers but has less stringent limitations on manuscript length and extent of graphic presentations.

- TECHNICAL MEMORANDUM. Scientific and technical findings that are preliminary or of specialized interest, e.g., quick release reports, working papers, and bibliographies that contain minimal annotation. Does not contain extensive analysis.

- CONTRACTOR REPORT. Scientific and technical findings by NASA-sponsored contractors and grantees.
- CONFERENCE PUBLICATION. Collected papers from scientific and technical conferences, symposia, seminars, or other meetings sponsored or cosponsored by NASA.

- SPECIAL PUBLICATION. Scientific, technical, or historical information from NASA programs, projects, and missions, often concerned with subjects having substantial public interest.

- TECHNICAL TRANSLATION. Englishlanguage translations of foreign scientific and technical material pertinent to NASA's mission.

Specialized services also include creating custom thesauri, building customized databases, organizing and publishing research results.

For more information about the NASA STI program, see the following:

- Access the NASA STI program home page at http://www.sti.nasa.gov

- E-mail your question to help@sti.nasa.gov

- Fax your question to the NASA STI Information Desk at 443-757-5803

- Phone the NASA STI Information Desk at 443-757-5802

- Write to: STI Information Desk NASA Center for AeroSpace Information 7115 Standard Drive Hanover, MD 21076-1320 
NASA/TM-2013-217821

\section{Aircraft Turbine Engine Control Research at NASA Glenn Research Center}

Sanjay Garg

Glenn Research Center, Cleveland, Ohio

National Aeronautics and

Space Administration

Glenn Research Center

Cleveland, Ohio 44135 
Trade names and trademarks are used in this report for identification only. Their usage does not constitute an official endorsement, either expressed or implied, by the National Aeronautics and Space Administration.

Level of Review: This material has been technically reviewed by technical management.

Available from

NASA Center for Aerospace Information 7115 Standard Drive

Hanover, MD 21076-1320
National Technical Information Service 5301 Shawnee Road Alexandria, VA 22312

Available electronically at http://www.sti.nasa.gov 


\title{
Aircraft Turbine Engine Control Research at NASA Glenn Research Center
}

\author{
Sanjay Garg \\ National Aeronautics and Space Administration \\ Glenn Research Center \\ Cleveland, Ohio 44135
}

\begin{abstract}
This paper provides an overview of the aircraft turbine engine control research at the NASA Glenn Research Center (GRC). A brief introduction to the engine control problem is first provided with a description of the state-of-the-art control law structure. A historical aspect of engine control development since the 1940s is then provided with a special emphasis on the contributions of GRC. With the increased emphasis on aircraft safety, enhanced performance, and affordability, as well as the need to reduce the environmental impact of aircraft, there are many new challenges being faced by the designers of aircraft propulsion systems. The Controls and Dynamics Branch (CDB) at GRC is leading and participating in various projects to develop advanced propulsion controls and diagnostics technologies that will help meet the challenging goals of NASA Aeronautics Research Mission programs. The rest of the paper provides an overview of the various CDB technology development activities in aircraft engine control and diagnostics, both current and some accomplished in the recent past. The motivation for each of the research efforts, the research approach, technical challenges, and the key progress to date are summarized.
\end{abstract}

\section{Introduction}

The modern dual spool turbofan engine used for commercial and military aircraft has evolved into its current form over the past 60 plus years, starting with the first U.S. jet engine, which was built in 1942 by General Electric based on the British Whittle turbojet engine. Controls technology has played a critical role in advancing the performance, reliability, operating life, and safety of modern aircraft engine. Jaw and Garg (2003) provides a broad historical overview of the propulsion control technology development in the United States. This paper will focus on the turbine engine control research done at the NASA Glenn Research Center (GRC). ${ }^{1}$

Simply stated, an engine control system determines the amount of fuel needed for the engine to produce a desired power (or thrust), based on pilot's power request through a throttle (or a power lever); it then meters the right amount of fuel to the engine's combustion chamber(s); and it maintains the engine power at the desired level in the presence of air flow disturbance and changes in flight conditions. The metering valve is usually called an actuator, whose position changes with the fuel flow command, and the fuel flow is called a control variable. Direct in-flight engine thrust measurements are not possible. So a good indicator of thrust, such as either engine shaft rotational speed $(\mathrm{N})$ or engine pressure ratio (EPR, defined as the ratio of engine exhaust (nozzle) total pressure to engine intake (fan face) total pressure), is controlled to provide effective thrust regulation. An aircraft engine is designed to operate in a wide operating envelope (to support aircraft mission profiles). Typically, the altitude can vary from sea level to 50,000 ft (or even higher), and for supersonic aircraft the air speed can go beyond Mach 3; furthermore,

\footnotetext{
${ }^{1}$ Although the center is referred to as "GRC" throughout this report, it has had different names throughout its 70-yr history. It began operations in 1942 under the National Advisory Committee for Aeronautics (NACA) as the Aircraft Engine Research Laboratory. The name was changed to the NACA Flight Propulsion Laboratory in 1947 and to the NACA Lewis Flight Propulsion Laboratory in 1948. When the NACA became part of the new National Aeronautics and Space Administration (NASA) in 1958, the name was changed to the NASA Lewis Research Center. Finally, the name was changed to the NASA John H. Glenn Research Center (GRC) in 1999.
} 
the air temperature at the same altitude and airspeed can vary from that on a hot summer day to a cold winter night. Additionally, the performance of a turbine engine deteriorates with usage because of component degradation caused by erosion, corrosion, foreign object ingestion, increased clearances between the rotating components and the seals, etc. The requirement for engine control is to ensure a minimum required level of performance, defined as the thrust achieved at a given throttle setting and given ambient conditions, throughout the operational envelope and certified operating life of the engine. This requirement for guaranteed performance with ambient condition variations and expected component degradations imposes severe challenges on control system design.

Engine operability constraints provide additional challenges for the control design. The control system has to ensure that the engine is operated safely; that is, without rotor overspeed, compressor stall, combustor blowout, or turbine overtemperature. This has to be done while maintaining acceptable acoustic and emissions levels. These considerations require nonlinear, often heuristic, control logic that complicates the problem further.

The main focus of discussion for this paper is the modern engine control referred to as "full authority digital engine control (FADEC). The term "full authority" implies that the computer-based controller has full authority over the command signals provided to the engine inputs with no manual override possible. The FADEC enables the pilot to move the throttle to any position during any operating phase of the airplane, and the control logic in the FADEC ensures that the engine will be able to operate safely. The term "full authority" stems from the fact that the early implementations of digital engine control had mechanical backup systems and/or capability for the pilot to override the digital control. This was to protect the engine from surging - a phenomenon during which the air flow in the compressor reverses, causing severe damage to the engine. Today's modern aircraft engines are typically equipped with dualchannel FADECs, with extensive built-in test functions for the control electronics, and some basic form of embedded engine analytical models to perform sensor and actuator validation checks.

This paper will focus on the control logic that is incorporated in the FADEC to provide safe and reliable operation of the engine throughout the operating envelope while also guaranteeing a certain operating life of the engine. Furthermore, this paper focuses on the high-bypass turbofans used in commercial aircraft. Typically an engine is certified to provide a minimum level of performance, thrust greater than a specified value for a given throttle setting at a given operating condition (ambient pressure and temperature), and a specified maximum thrust rise time for throttle movement from idle to maximum thrust setting. For commercial aircraft, a typical engine operating cycle consists of modulating the thrust from idle to maximum thrust for takeoff, setting the desired thrust levels for climb and cruise, and then setting the engine to idle for landing. As will be discussed later in this paper, the control logic plays a critical role in meeting these performance guarantees while ensuring safe operation of the engine.

The paper is organized as follows. First a brief description of the state of the art of engine control is provided to familiarize the reader with the challenges of engine control design and how these are currently addressed. Historical contributions by GRC in the early stages of turbine engine technology development and then as technology advanced from hydro-mechanical to digital control are summarized. Major control technology developments recently completed by the Controls and Dynamics Branch (CDB) at GRC, and current ongoing research efforts are then described. A brief description of past GRC technology development for rocket engine control and current CDB technology development for fault management of space exploration systems is provided to give the reader an overall perspective of propulsion control technology development at GRC. The paper concludes with a summary of the discussed accomplishments and a look into the future of aircraft engine control.

\section{State of the Art of Engine Control}

The intent of this brief overview of turbofan engine operation is to provide the reader with some context of the challenges associated with engine control. Spang and Brown (1999), DeCastro et al. (2008), and Jaw and Mattingly (2009) will enable the reader to gain a more complete understanding of this background information. The discussion in this section is based on the material in DeCastro et al. (2008). 


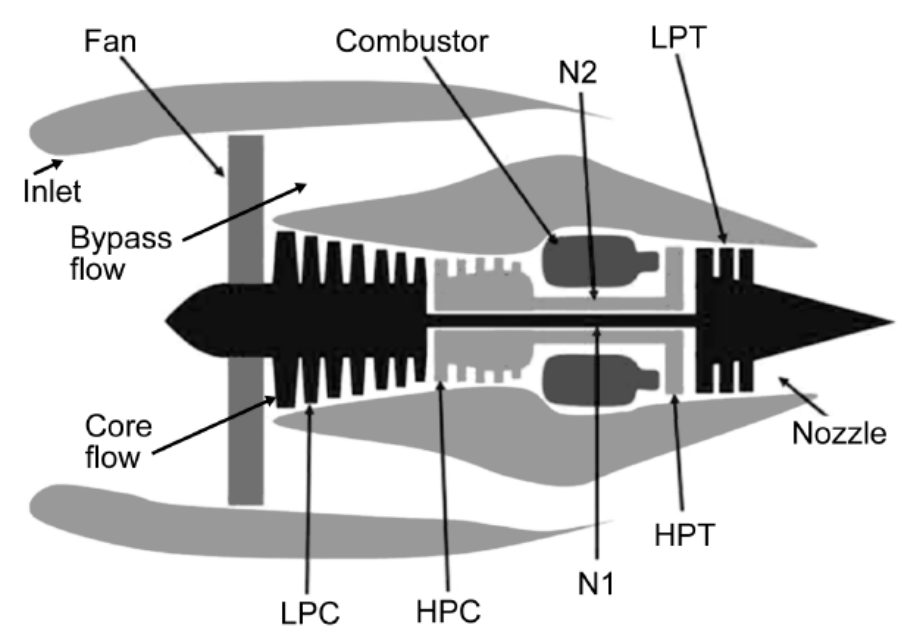

Figure 1.-High-bypass twin spool turbofan engine: N1 and N2 are fan and core speeds; LPT, low-pressure turbine; LPC, low-pressure compressor; HPC, high-pressure compressor; and HPT, high-pressure turbine (image courtesy of NASA).

Figure 1 shows a schematic of a modern high-bypass dual-spool commercial aircraft turbofan engine. The air supplied by the inlet to the engine is compressed by the fan. A major portion of this compressed air is ducted to the outer gas flow path, referred to as "bypass air," while the rest is routed to the engine core. The core air is further compressed by two multi-stage compressors: the low pressure compressor (LPC) and high pressure compressor (HPC). The compressed air is mixed with fuel and burned in the combustor. The two turbines, high pressure turbine (HPT) and low pressure turbine (LPT), extract energy from the hot combustor air and convert it to mechanical (rotational) energy. The LPT drives the LPC and the fan while the HPT drives the HPC. The core air is expanded through the nozzle. In this engine configuration, the bypass air exhausted over the engine core creates most of the thrust. The bypass ratio is the ratio of the flow rate of the fan compressed air going through the bypass duct to the flow rate of the core air. The turbofan engine achieves fuel-efficient operation by accelerating a large amount of air through a small velocity change. Having a large proportion of thrust generated by the low-velocity air also makes the high-bypass turbofan much quieter. In Figure 1, N1 and N2 refer to the speeds of the two spools with N1 being fan speed and N2 being the core speed. Note that in general N1 is much lower than N2.

Although fuel flow is the main control variable to set the engine operation for a desired level of thrust, typical modern engines have other control variables such as a variable bleed valve (VBV) and variable stator vanes (VSV) to allow for safe and efficient operation of the engine. The VBV is to prevent the LPC from entering stall at any operating condition by providing pressure relief at the LPC exit. The VSV are typically located at the forward stages of the HPC and are used as a means to maintain compressor stability and prevent choking of the downstream compressor stages. These other control variables are typically scheduled as a function of the engine operating condition and are not used for direct feedback control.

Since the turbofan engine is a thermo-mechanical device, there are various limitations on its operation. Some of the limits of concern from a control perspective are structural and operational limits. To maintain the structural integrity of the rotating components, there is a maximum limit on the allowable fan and core shaft speeds. Also, since the blades in the first stator stage of the HPT see the highest flow temperatures (at the exit of the combustor), the maximum temperature at turbine inlet (T41) has to be limited to prevent the blades from getting hot enough to lose structural integrity. Operational limits consist of ensuring that: (1) adequate stall margins are maintained for the LPC and HPC throughout the engine operating envelope to prevent the compressors from approaching stall during engine transients; and (2) a minimum fuel flow is maintained at any operating condition to prevent combustor blowout. 
From an acceptable operating life perspective, the maximum T41 is further restricted to prevent excessive thermo-mechanical fatigue damage to the turbine components.

The objective of the control logic design is to provide acceptable performance while ensuring that the engine operation remains within the structural and operational limits. The engine control logic should provide smooth, stable, and stall-free operation of the engine via a single pilot input-throttle or power lever angle (PLA) — with no restrictions on throttle movement. Furthermore, it should provide reliable and predictable throttle movement to thrust response throughout the engine operating life. Some of the challenges in engine control design are

- Thrust, the primary controlled variable of interest cannot be measured.

- Changes in ambient condition and aircraft maneuvers cause distortion of flow into the fan/compressor, so the engine control has to be robust under these conditions.

- Parameters that need to be limited, such as turbine inlet temperature, minimum stall margin, etc., cannot be directly measured.

- Engine components degrade with usage, so the control logic has to be robust to provide guaranteed performance in the presence of these significant component degradations. One approach to estimate the effect of these degradations on engine performance is to model the effects through a set of influence coefficients called health parameters (Jaw and Mattingly 2009; Urban 1974).

Additionally, the harsh operating environment of the engine, high temperatures and large vibrations, places certain constraints on the control hardware. One constraint important for control logic development is the limitation it places on the number and type of sensors that can be placed on the engine. A typical engine control system has 6 or 7 sensors including the two rotor speeds (N1 and N2), pressure and temperature measurements at 2 or 3 engine locations such as the fan inlet and LPC and HPC exits, and an exhaust gas temperature (EGT) sensor, which measures the gas temperature at the exit of the LPT. As an engine ages with use, the clearance between the turbine blade tips and the turbine casings open up, increasing the amount of hot air leaking through the turbine and resulting in an increase in EGT. The EGT then provides a direct indication of the remaining useful engine life.

A typical modern engine control logic is shown in the block diagram of Figure 2. Since thrust cannot be directly measured, a variable which can be sensed and is directly correlated with engine thrust is selected to be the primary controlled variable through the PLA. Figure 2 shows the engine fan speed (N1) as the primary controlled variable. Note that since the majority of the thrust in commercial turbofan

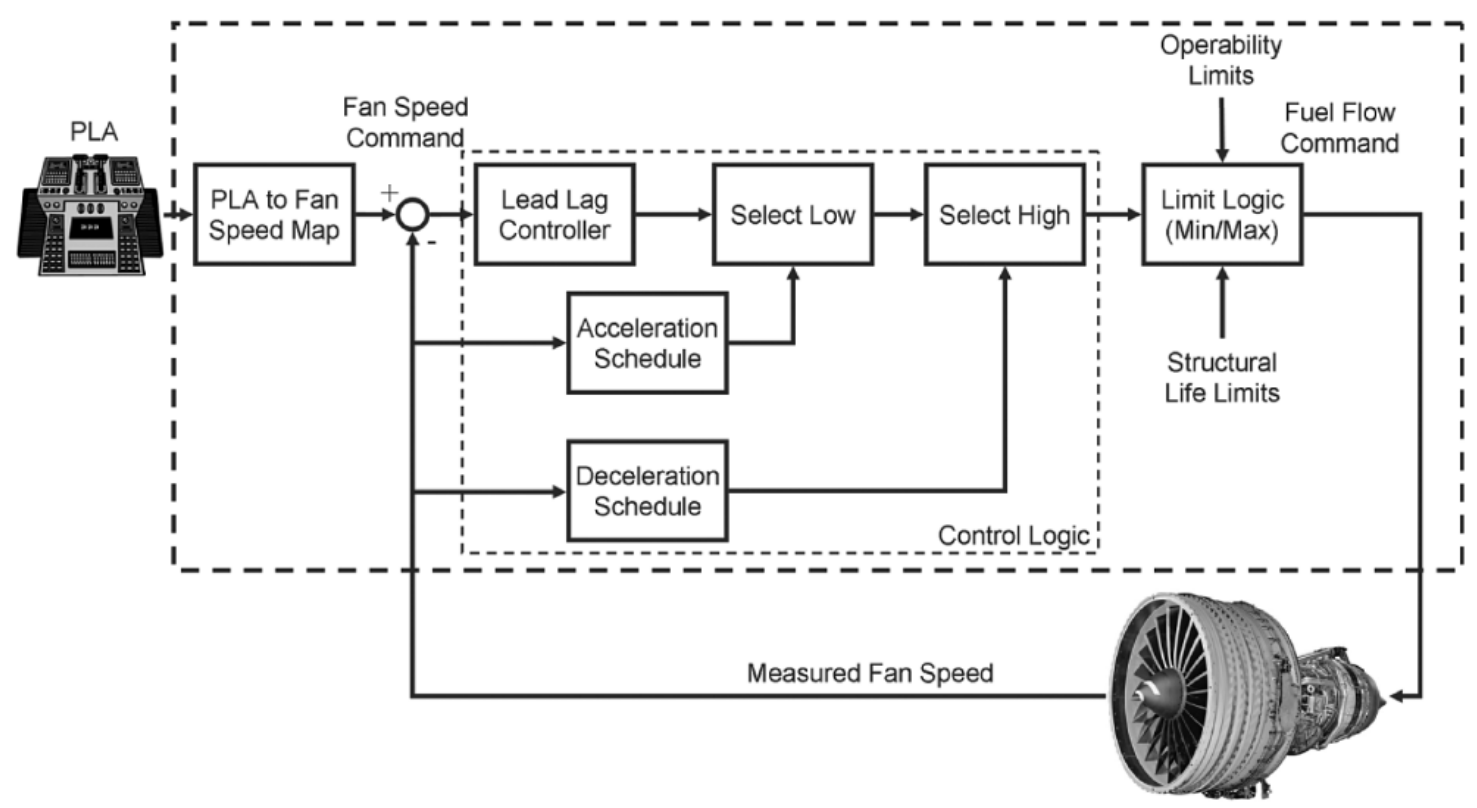

Figure 2.-Block diagram of typical modern engine control logic (image courtesy of NASA). 


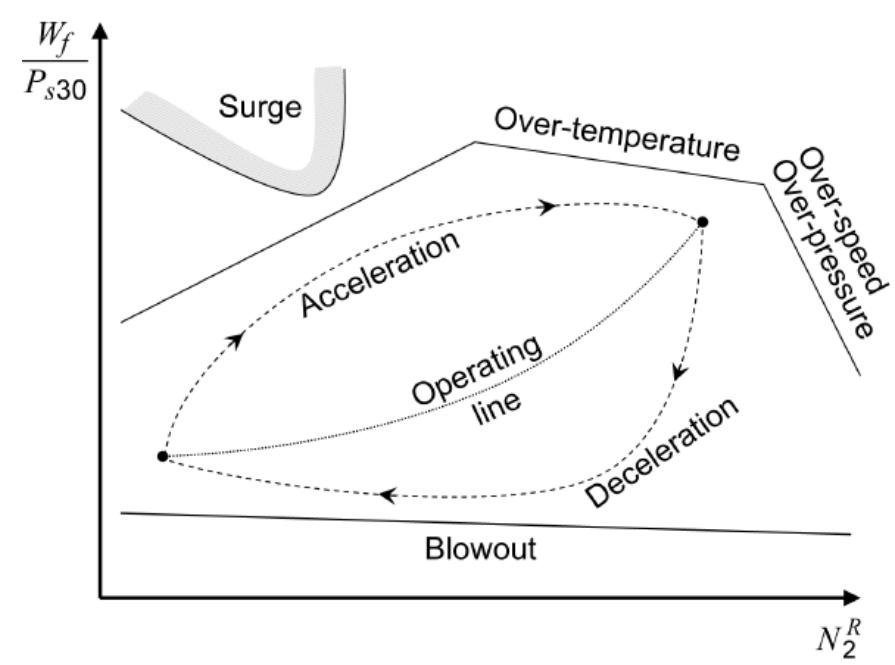

Figure 3.-Engine limit protection implementation philosophy: $W_{f} / P_{\text {s30 }}$ is ratio of fuel flow to combustor inlet pressure and $N_{2}^{R}$ is corrected core engine speed (image courtesy of NASA).

engines is created from the fan bypass flow, $\mathrm{N} 1$ is an appropriate variable to regulate to achieve the desired throttle to thrust response. Another variable that can be used as the primary controlled variable is the engine pressure ratio (EPR), defined as the ratio of the pressure at the LPT exit to the pressure at the fan inlet. In Figure 2, a PLA setting creates a reference command for N1 and a simple lead-lag compensator creates a fuel flow command based on the difference between the commanded and measured fan speed. However, this command cannot be implemented as is because, as discussed earlier, the engine structural and operational limits need to be taken into consideration. The acceleration and deceleration schedules are implemented primarily to prevent compressor stall during transients. Secondarily, the acceleration limit is an additional measure to prevent overstress of the rotor, and the deceleration limit protects against combustor blowout. These schedules are a function of the corrected core engine speed ( $N_{2}^{R}$; see Mattingly (1996) for details on how engine performance parameters are corrected to the sealevel standard day condition to take out the variability due to operating condition) and impose a limit on the ratio of fuel flow to combustor inlet pressure $\left(W_{f} / P_{\mathrm{s} 30}\right)$ since this ratio, which can be computed from measurements, relates closely to surge and temperature margins. Figure 3 shows a typical example of how these schedules protect the engine operation from violating the structural and operational limits.

Since the acceleration schedule imposes a maximum limit on the fuel flow, the lower of the fuel flow imposed by the acceleration limit and that required to track the regulated variable is selected through the "Select Low" block in Figure 2. The output of this block is compared with the minimum fuel flow command required to stay within the deceleration limit, and the higher value is selected through the "Select High" block. The output of the "Select High" block is further compared with the fuel flow required to stay within additional limits, such as the maximum core speed, etc., and the selected incremental fuel flow is sent as the command to the fuel pump and metering system. This Min-Max selection control architecture ensures that the fuel flow command sent to the fuel flow actuation system is such that the engine operation will avoid exceeding any of the limits.

The engine acceleration and deceleration schedules are determined though simulation and analytical studies, and the engine set-point schedules are selected such that the desired performance setting can be achieved without operating on a limit in the steady state. The performance variable regulation and other limit variable regulation is typically implemented through PI (proportional + integral) control with the control gains designed using linear models and scheduled typically as a function of PLA and Mach no. and other additional variables that define the engine set point. Engine control design is developed and 
evaluated using dynamic engine models. The following provides a brief overview of the engine dynamic modeling. The interested reader can find details in DeCastro et al. (2008) and the references therein. Steady-state engine performance is obtained from cycle calculations derived from component performance maps obtained through detailed component modeling and component tests. Corrected parameter techniques are used to reduce the number of points that need to be evaluated to estimate engine performance throughout the operating envelope. Dynamics are modeled through inertia (the rotor speeds), combustion delays, heat soak and sink modeling, etc. This is a computationally intensive process since it is important to maintain mass/momentum/energy balance through each component. A detailed thermodynamic cycle deck is developed using this procedure and parameters within this model are adjusted based on experimental data to match the tested engine performance characteristics. Simplified models from this thermo-cycle deck are generated to develop and evaluate the control logic. The control design is evaluated throughout the operating envelope using a nonlinear aerothermal engine simulation and for engines at various levels of condition in the operating life, as modeled through the variation of health parameters.

One of the typical transient test cases for engine control is "burst-chop" wherein the PLA is moved from idle to full (burst), and a few seconds later it is moved back to idle (chop). The burst-chop results from the nonlinear engine simulation evaluation for the control design discussed in DeCastro et al. (2008) are shown in Figure 4. In Figure 4, TRA stands for throttle resolver angle, which is analogous to PLA discussed earlier, $N_{f}$ and $N_{c}$ are fan and core speeds, respectively, and $T_{48}$ is the exhaust gas temperature.
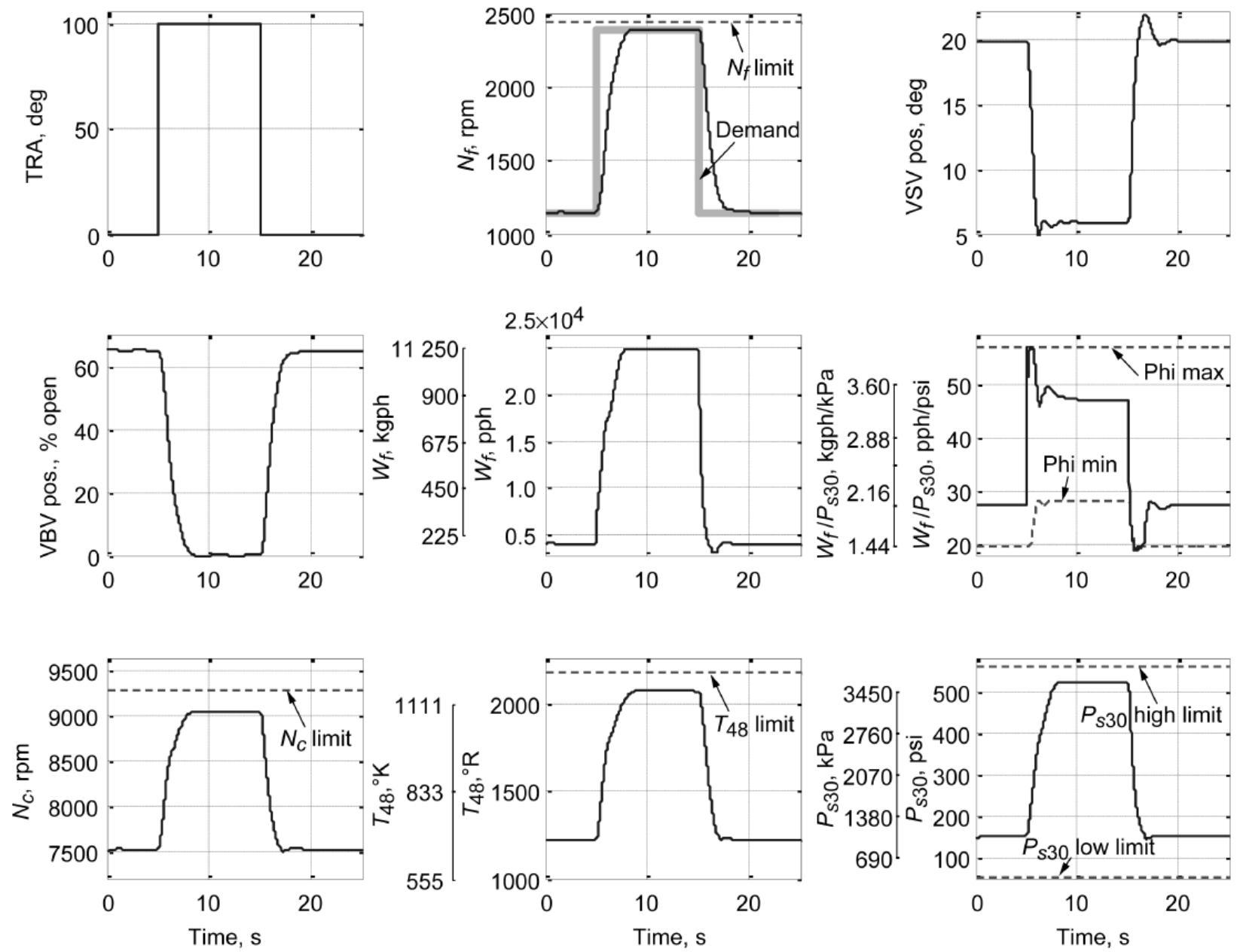

Figure 4.-Engine response for burst and chop (from DeCastro et al. 2008; courtesy NASA): $N_{f}$ and $N_{c}$ are fan and core speeds, respectively; $T_{48}$, exhaust gas temperature; and $W_{f} / P_{s 30}$, ratio of fuel flow to combustor inlet pressure. 
The plots in Figure 4 show that the fan-speed compensator (in control the majority of the time) produces a smooth fan speed response that does not violate any limits. The VBV and VSV actuators follow schedules that are inversely proportional to the corrected fan and core speeds, respectively. The only limiter that comes into play is the $\mathrm{Wf} / \mathrm{Ps}_{30}$ saturation limit; the maximum limit (Phi max to protect against stall and temperature limits) is encountered during burst, and the minimum (Phi min to protect against combustor blowout) is encountered during chop.

Once the control design is determined to meet the requirements in terms of providing acceptable performance without violating any of the structural and operational limits, it is coded into software for implementation into the control hardware. The control gains are further adjusted based on engine ground and altitude tests and finally flight tests before releasing a product version of the control logic.

\section{Historical GRC Contributions}

The year 2003 commemorated the $100^{\text {th }}$ anniversary of the Wright brothers' flight-the first powered flight where both the airplane and the engine were designed and built by the Wright brothers. This first powered flight sparked enthusiasm about aviation around the world, leading to development of a mature industry that has revolutionized transportation. In the past 100 years, aviation has become a symbol of innovation with record-setting breakthroughs, many of which were contributed by advances in engines or propulsion systems. During this period, propulsion systems have evolved from piston engines (the first generation, 1903-1945) to jet engines (Garvin 1998; Mattingly 1996) (1942-present). GRC, since its inception in 1941, has made significant contributions to the development of engine control—both enhancing the fundamental understanding of engine dynamic performance and conducting research on concepts that improved the performance and safety of turbine engines. This section provides a brief overview of some of the most critical contributions. The section is divided into two subsections: early stages of turbine engine control (1945-1960s) and maturation of turbine engine control (1970-1990).

\section{Early Stages of Turbine Engine Control (1945-60s)}

In 1948, General Electric (GE) tested the first afterburning turbojet engine in the world, the J47. The engine incorporated a hydromechanical fuel control for the main combustion chamber and an electronic (vacuum tube) fuel control for the afterburner. The original control law for the J47 was designed using only frequency response techniques. The engine underwent altitude testing at GRC. During the testing, it was found that the noise in the speed sensor, coupled with the high gain of the speed governor, caused the engine to limit cycle. To solve this problem, GE and NASA engineers worked together and applied the time-domain step response analysis method. The problem was soon fixed by reducing the control gain at altitude. This industry-government cooperation experience established a good foundation for building a knowledge base for engine controls that continues today. Some other major GRC contributions during this time period are briefly described below.

\section{Corrected Parameters for Model Simplification}

Engine steady-state performance was obtained from cycle calculations using component performance maps derived from component test results, constant specific heat gas properties, and an iterative process for balancing internal engine flow and energy transfers. Performance calculations at each engine operating point could take several hours by slide rule or desk calculator. Generating an engine performance map for the entire operating envelope (altitude and Mach no.) would take months. Also, it was impractical to collect experimental data at the large number of possible operating points. The concept of corrected parameter techniques (corrected flows and speeds, temperature ratios, and pressure ratios) was developed by NASA engineers to reduce the number of operating points needed to be evaluated to 
define engine operation over the engine’s operating envelope (Mattingly 1996). The corrected parameter approach considerably reduced the amount of experimental data that needed to be collected and the time it took to perform the calculations to develop a complete engine performance map. The corrected parameter technique is being used to this day for efficient control design and analysis.

\section{Simplified Dynamic Model of Engine Response}

The early engine control was a hydromechanical governor, which metered the fuel flow going into the engine to be proportional to the difference between the set shaft speed and the actual speed of the turbine. The governor design was determined experimentally so that the proportional gain provided by the governor will provide a well-damped response. Dynamic behavior of the single-shaft turbojet engine was first studied at GRC in 1948. The study focused on the dynamics of the shaft speed, because it is almost analogous to thrust and can be more easily and more accurately measured. The study showed that the dynamic characteristic of a turbojet engine (i.e., the transfer function from fuel flow to engine speed) can be represented by a first-order lag linear system with a time constant (Otto and Taylor 1950). The results from Otto and Taylor (1950) are summarized in Figure 5, which shows the experimental and calculated results for corrected engine time constant as a function of the corrected engine fan speed. This early analysis allowed the use of feedback control theory to design the control gains and significantly reduced the experimental iteration needed to achieve the desired closed-loop response. The first-order approximation of the engine response, with the time constant as a function of the operating condition, is still used today to generate simplified engine models that can be integrated with aircraft simulations for real-time piloted simulation evaluations of aircraft performance.

\section{Real-Time Engine Dynamic Modeling Using Computers}

In 1951, Pratt \& Whitney (PW) flight-tested the first two-spool turbojet engine in the world, the J57, which helped achieve supersonic speed on a YF-100 aircraft. As engine capabilities advanced in the 1950s, engine control technologies also advanced to deliver the new capabilities. As the engine technology matured to high compression ratio, by-pass flow turbofans during this period, the control technology also matured to variable geometry controls (e.g., the compressor stator control and intake and nozzle controls). With multiple control effectors, the design of control logic became too complicated to be performed and evaluated entirely through testing. The simultaneous emergence of computer technology provided the opportunity to develop computer-based real-time dynamic simulations of engines, which could then be used for control design and analysis. Initial development of simulations of the dynamic

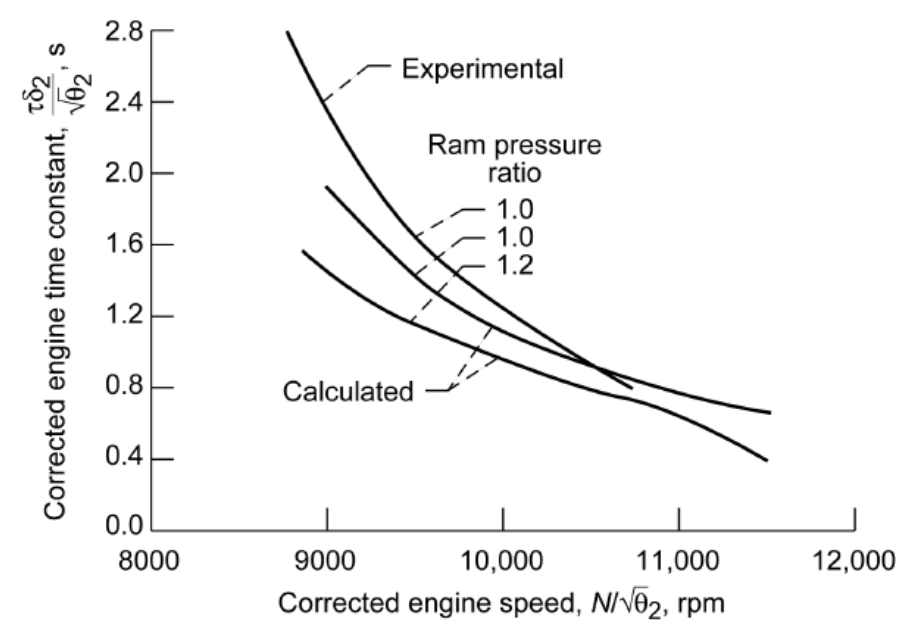

Figure 5.-Corrected engine time constant as a function of corrected engine speed (from Otto and Taylor 1950; courtesy NASA). 


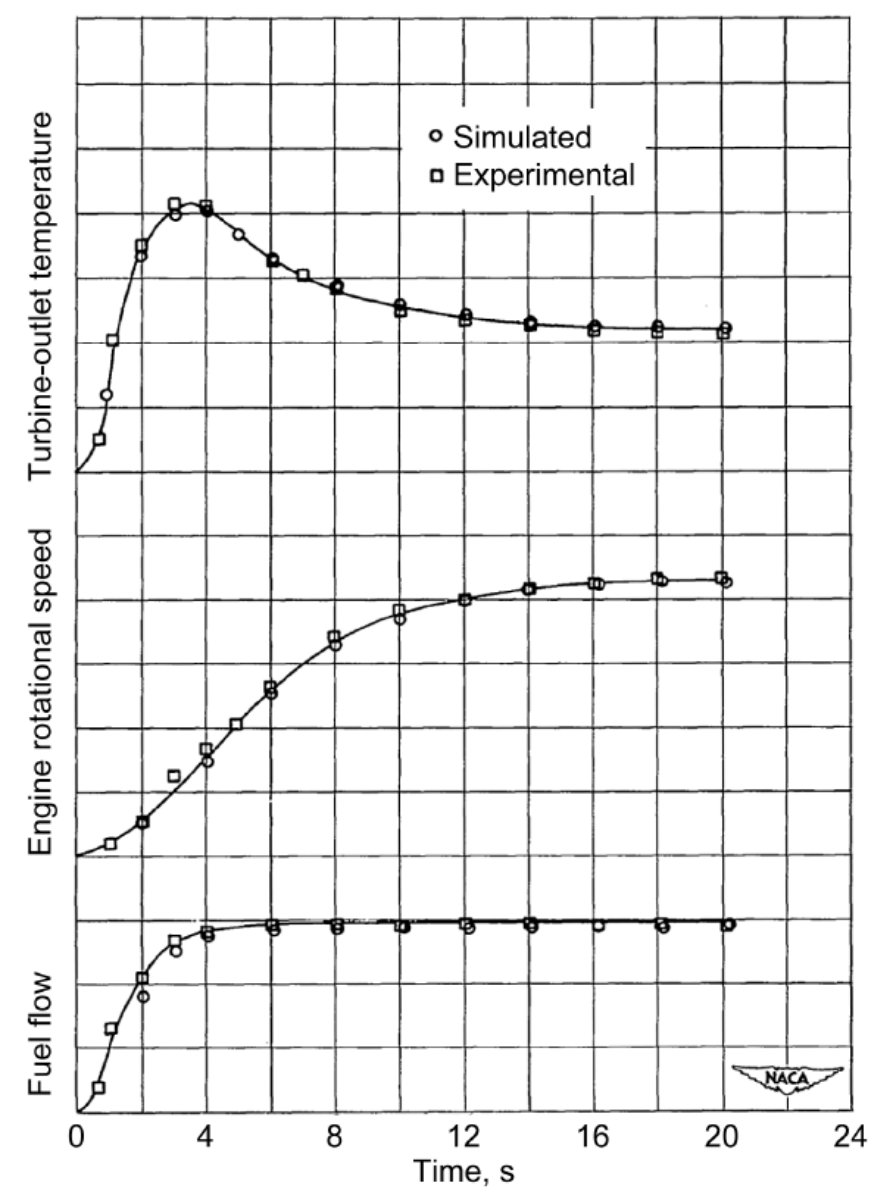

Figure 6.-Comparison of simulated and experimental responses of turbojet engine (from Ketchum and Craig 1952; courtesy NASA).

performance of gas turbine engines was achieved through the use of electronic analog computers at GRC in the early 1950s. During this time, the response of a turbojet engine to a step change in fuel flow was simulated and the results were validated experimentally (Ketchum and Craig 1952). Figure 6 shows an example result from Ketchum and Craig (1952). The confidence generated through this initial effort in the capability to be able to accurately simulate complex engine dynamic behavior led to further advancements in the simulation methods and helped keep the time and cost of control design development and validation commensurate with that for other technologies.

\section{Maturation of Turbine Engine Control (1970-1990)}

As engine control functionality expanded, control system complexity also increased. Control complexity is reflected by the number of controlled variables managed by a control system. As control complexity increased, the traditional hydromechanical fuel control and servo components, although having been proven as highly reliable, were quickly reaching a practical limit; that is, they became increasingly bigger, heavier, and more expensive to be practical for aircraft engine controls. The emerging electronics and computer industry provided an opportunity to transition engine control from hydromechanical to computer based. In the early 1970s, analog and digital electronic control units (ECU) were designed to provide high-level supervisory functions. These supervisory control units primarily calculated speed or temperature set-points throughout the engine operating envelope. For some noncritical controlled variables, they would have sole control responsibilities. Early production supervisory control 
units included: the digital electronic engine control (DEEC) unit for the PW F100 and the analog augmentor fan temperature (AFT) control for the GE F101. With the confidence built in using ECUs for engines, there was interest in adding additional capability to further enhance engine performance and provide fault tolerance capabilities. Some of the key GRC contributions for engine control and diagnostics during this period are summarized below.

\section{Digital Electronic Engine Control (DEEC)}

In the early 1980s, NASA in collaboration with the U.S. Air Force and Pratt \& Whitney conducted flight investigation of a DEEC system on an F100 engine in an F-15 airplane (Burcham et al. 1984). The DEEC was developed under PW Internal Research and Development Funds, altitude facility tests were conducted at GRC, and flight tests were conducted at NASA Dryden Flight Research Center (DFRC). The following is a summary of testing at GRC from paper No. 4, "NASA Lewis F100 Engine Testing," in Burcham et al. (1984). Two builds of an F100 engine model derivative were evaluated in the Propulsion System Laboratory (PSL) altitude facility for improvements in engine components and DEEC control logic. Two DEEC flight logics were verified throughout the flight envelope in support of flight clearance for the tests on the F-15: a nozzle instability and a faster augmentor transient capability were successfully investigated in support of the F-15 DEEC flight program. Also included in the testing were identification of an off-schedule coupled-system mode fan flutter, DEEC noseboom pressure correlation, DEEC station 6 pressure comparison, and a new compressor inlet variable vane (CIVV) schedule. Following the altitude testing at GRC, a 30-flight test program was conducted at DFRC. The results of the testing showed the DEEC to be a very capable controller for the F100 engine. This test program led to the introduction of digital engine control on military engines and ultimately to the introduction of the current-generation FADECs on commercial aircraft engines with the control logic as described in the earlier section of this paper. As mentioned earlier, the term "full authority" implies that the pilot has no restrictions on throttle movement throughout the aircraft flight envelope, and the engine controller maintains full authority to ensure safe operation of the engine. Prior to the introduction of the FADECs, the pilot typically needed to keep the throttle movements within cleared safety limits for a given flight condition in order to prevent engine stall.

\section{Multivariable Engine Control Development}

The successful DEEC testing on the F100 engine led to various research efforts to improve the functionality of digital engine control. One of these efforts focused on application of emerging multivariable control design techniques to the engine control problem. Air Force Wright Aeronautical Laboratory (AFWAL), now part of Air Force Research Laboratory (AFRL), and GRC jointly sponsored the Multivariable Control Synthesis (MVCS) program from 1975 to 1978. The program developed a series of Linear Quadratic Regulators (LQRs) and connected them with simple transition logic and several operating limits to achieve effective large-transient controls. The control design (DeHoff et al. 1977) (see Fig. 7) was verified extensively at NASA’s hybrid simulation facility (Szuch et al. 1977), and followed by a successful testing on an F100 engine in the GRC altitude test facilities (Lehtinen et al. 1979). As discussed in an earlier section, even the current commercial engine control logic consists of controlling just the fuel flow (WF) in a "closed-loop" (feedback) manner, with the other variable geometry effectors such as inlet guide vanes on an "open-loop” schedule based on measured parameters that define the operating conditions. The F100 engine had considerable variable geometry including compressor inlet variable vanes (CIVV), rear compressor variable vanes (RCCV), nozzle jet area $\left(A_{j}\right)$, and also customer bleed flow (CBF), which affected engine performance. Under the multivariable control design approach, all the engine sensors are used as input to control logic to generate commands for all the control effectors. The objective is to keep the engine operating at its maximum possible efficiency at each operating point. Testing on the F100 engine in the GRC altitude facility indicated that the engine could be successfully and safely controlled using MVCS. However, the performance benefits of the MVCS were 


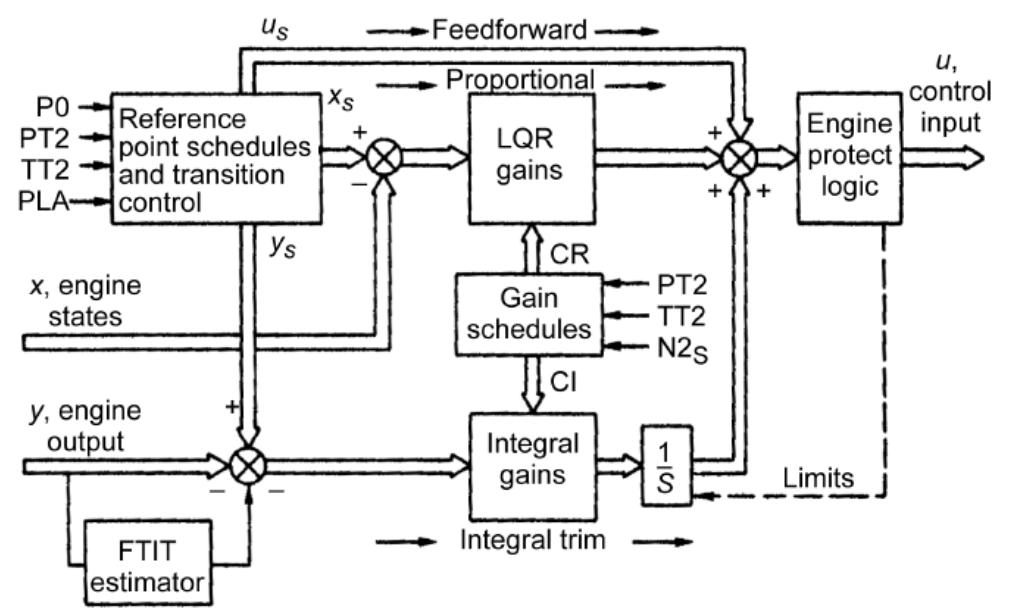

Figure 7.-F 100 LQR control block diagram (from Lehtinen et al. 1979; courtesy NASA; acronyms are defined in the reference).

not commensurate with the complexity of the control design and implementation. So MVCS did not make the transition to operating F100 engines. Since this MVCS study, multiple research studies have been done on multivariable control of engines (e.g., see Polly et al. 1988); however, this technology has not yet made a transition to currently flying engines except for the two-input two-output multivariable control on the F414-GE-400 engine for the U.S. Navy F18 aircraft. The reason is that there is sufficient bandwidth separation between the control effectors to negate any benefits of using multivariable control. The author has been told in verbal communications by industry researchers that PW has implemented an advanced multivariable control for the F135 engine; however, no detailed information is publicly available. Also, to the author's best knowledge, no detailed information about the multivariable control on the F414-GE-400 engine is publicly available.

\section{Sensor Fault Detection, Isolation, and Accommodation}

In 1970, the F100 was the first engine equipped with an onboard event history recorder (EHR). This recorder was the predecessor of the engine diagnostic unit (EDU) installed on later models of the engine in 1980s. The EDU and the DEEC together perform the engine monitoring system (EMS) function. The EMS provides the user with information on engine condition and engine life usage data. The engine condition data is used to isolate faulty components or systems during engine troubleshooting. The initial success in applying multivariable control design methods to jet engines prompted the AFWAL to explore failure detection and accommodation techniques (Small 1982). In the early 1980s, GRC explored an advanced approach to sensor failure detection under the Advanced Detection, Isolation and Accommodation (ADIA) program (Merrill et al. 1988). The objective of the program was to improve the overall demonstrated reliability of digital electronic control systems for turbine engines by detecting, isolating, and accommodating sensor failures using analytical redundancy methods. The program focused on sensor failures because the engine sensors are among the least reliable control components. The ADIA algorithm consisted of three elements: (1) hard sensor failure detection and isolation logic, (2) soft sensor failure detection and isolation logic, and (3) an accommodation filter. Hard failures are defined as out-ofrange or large bias errors that occur instantaneously in the sensed values. Soft failures are defined as small bias errors or drift errors that increase relatively slowly with time. The accommodation filter incorporates an engine model along with a Kalman filter to generate estimates of the engine states and outputs. The ADIA algorithm was integrated with an existing microcomputer implementation of the F100 multivariable control algorithm, and a real-time simulation evaluation of the algorithm was performed using a hybrid computer simulation of a F100 engine (Merrill et al. 1988). The success of the real-time evaluation provided the confidence to proceed with testing and evaluation of the ADIA algorithms on an F100 engine in the GRC altitude test chamber. Engine sensor failure detection and accommodation were 
demonstrated at two power conditions (Merill et al. 1987). Transient engine operation over the full power range with a single sensor failed and accommodated was successfully demonstrated. The GRC team and industry partners in the ADIA program received the prestigious R\&D 100 award for this technology development and demonstration. Although the ADIA approach is not yet fully implemented in currently operating engine control systems because of the processing power required for full envelope implementation as well as certification issues with using a model-based sensor estimate for engine control, some elements of this technology were incorporated in the FADEC logic for sensor failure detection and isolation.

\section{Advanced Engine Control}

With the success of the F100 MVCS and ADIA programs, there was renewed interest at GRC in investing in engine control technologies. The Controls group grew significantly during the 1990s with a multitude of technology development efforts under various NASA programs and in collaboration with Air Force research programs. The current Controls and Dynamics Branch (CDB) started with a modest complement of 5 staff members in the mid-1980s, and currently consists of 14 civil servants and 8 contractors with additional support being provided by various employees from other GRC organizations. The research emphasis was on how to apply emerging multivariable and intelligent control approaches to provide improved functionality and performance for engines. The number of sensors and actuators on the engines continued to increase, thus providing an opportunity for advanced controls research. The continued advancement in computer technology also opened the possibilities of incorporating more complexity into the control logic in the FADECs. The idea of using active control of engine components to maximize the achievable performance throughout the operating envelope, and not be constrained to accept the suboptimal performance at other than design points, began to emerge. With the reorganization of NASA Aeronautics Research Mission programs in 2006, there was additional opportunity to investigate nontraditional uses of the engines, enabled through advanced controls, to increase aviation safety, and to start formulating engine control architectures that will help meet the challenging goals of increased efficiency and reduced environmental impact. Some of the significant accomplishments of CDB in the mid-1990s to early 2000s are described in this section, followed by a brief description of the main current research efforts.

\section{Recent Significant Accomplishments}

\section{Integrated Flight/Propulsion Control}

In the mid-1980s to 1990s, the trend in future military fighter/tactical aircraft design was towards aircraft with new/enhanced maneuver capabilities such as short takeoff and vertical landing (STOVL) and high-angle-of-attack performance. An integrated flight/propulsion control (IFPC) system is required in order to obtain these enhanced capabilities with reasonable pilot workload. Under an AFWAL sponsored "Design Methods for Integrated Systems” (DMICS) program in the mid-1980s, two contractor teams had developed two very different approaches to IFPC design: (1) a centralized approach based on the Linear Quadratic Gaussian/Loop Transfer Recovery (LQG/LTR) method (Smith 1986) and (2) a decentralized, hierarchical approach using LQR-based explicit model-following for control synthesis (Shaw et al. 1988). In the late 1980s, NASA in collaboration with the U.S. Air Force started a concerted effort on investigating IFPC designs for advanced short takeoff vertical landing (ASTOVL) aircraft with supersonic cruise capability. Two contractor teams, each consisting of an airplane and an engine company, developed IFPC designs for two different conceptual ASTOVL aircraft with a view towards evaluating them in piloted simulations in the Vertical Motion Simulator (VMS) at the NASA Ames Research Center (ARC). In parallel, GRC started an in-house STOVL/IFPC program to develop advanced IFPC design methods based on the lessons learned from the DMICS studies. The GRC-developed IFPC design approach combined the best aspects of the two DMICS studies and was referred to as Integrated 
Methodology for Propulsion and Airframe Control (IMPAC) (Garg et al. 1991). The major IMPAC design steps are (1) generation of integrated airframe/engine models for control design; (2) centralized control design, considering the airframe and engine system as an integrated system; (3) partitioning of the centralized controller into separate airframe and engine subcontrollers; (4) Operational flight envelope expansion through scheduling of the partitioned subcontrollers; (5) nonlinear design such as incorporation of limit logic for operational safety; and (6) full system controller assembly and evaluation.

The IMPAC approach was applied for IFPC design for a conceptual ASTOVL aircraft in the landing approach to hover transition flight phase (Garg and Mattern 1994). During this phase the control of the aircraft transitions from forces and moments generated by aerodynamic control effectors to purely propulsion system generated forces and moments. The ASTOVL aircraft concept had multiple control effectors including left and right elevons used collectively as elevator and differentially as ailerons; a rudder; ejectors on the wing to provide propulsive lift at low speeds and hover; a two-dimensional convergent-divergent (2D-CD) vectoring aft nozzle; a vectoring ventral nozzle for pitch control and lift augmentation during transition; and jet reaction control systems (RCS) for pitch, roll, and yaw control during transition and hover. During the transition flight phase, all these control effectors are active, and it is quite a complex problem to coordinate their usage in a way that is transparent to the pilot and also provides the aircraft response characteristics, which allow the pilot to complete landing-related tasks successfully within acceptable workload. The IFPC design developed using the IMPAC approach was evaluated in a fixed-base piloted simulator at GRC (Bright et al. 1994). In the simulation, the pilots successfully completed typical transition phase tasks such as combined constant deceleration with flight path tracking and constant acceleration wave-off maneuvers. The pilots could successfully perform abort sequences and maneuverability tasks without loss of control predictability or excessive workload.

Various technologies that are relevant to practical use of multivariable control design techniques were developed as part of the IMPAC-based IFPC design study (Garg and Mattern 1994). These are (1) a generic command tracking problem framework for robust control law synthesis using H-infinity control design techniques with rules of thumb for selecting various frequency weights in the design procedure; (2) a systematic procedure for partitioning a centralized controller into decentralized, hierarchical subsystem controllers; (3) a simplified scheme for controller scheduling, which exploits the robustness properties of centralized/partitioned control designs; and (4) a modified scheme for designing integrator wind-up protection (IWP) gains, which guarantees closed-loop system stability for single-actuator saturation. An example result which shows application of the optimized IWP technique to the propulsion control portion of the STOVL IFPC design (Mattern and Garg 1992) is shown in Figure 8.

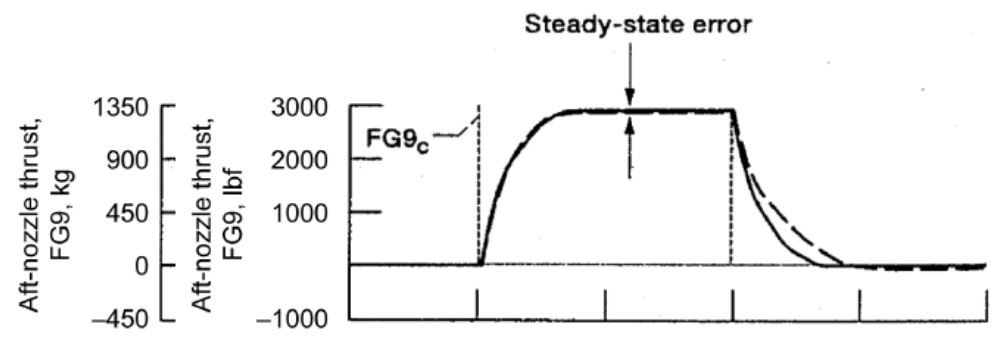

(a) Steady-state error.

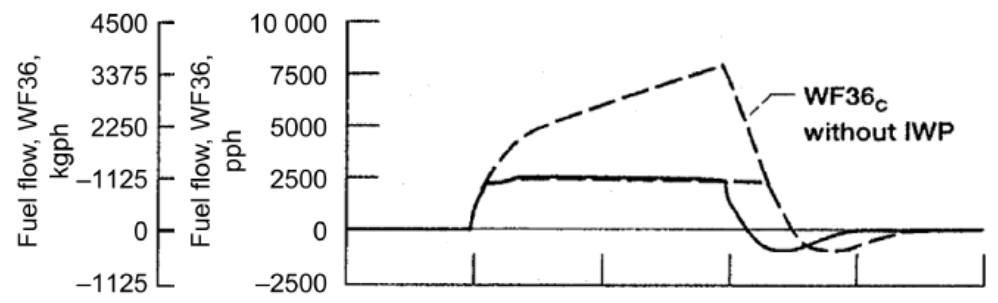

(b) Corresponding limited fuel flows.

Figure 8.- Integrator wind-up protection for engine control (from Mattern and Garg 1992; courtesy NASA). 
Shown are the responses of the aft nozzle thrust (FG9) to a step command and the corresponding fuel flow (WF36) requirement with and without the IWP. Without IWP (dashed lines), when the fuel flow limit is encountered, the fuel flow command continues to grow because of integrator wind up. As the FG9 command is reduced to zero, the integrator takes time to wind down and the FG9 response is degraded. With IWP active (solid lines), the fuel flow command tracks the fuel flow limit, and good FG9 tracking performance is obtained when the step command is removed. Although IMPAC methodology was successfully demonstrated by NASA, its application to current and future aircraft configurations was perceived as too complex during industry evaluation. However, the technologies developed for practical application of multivariable control design techniques were perceived to be of value by the industry and were transferred to industry through joint studies as documented in Watts and Garg (1995) and Frederick et al. (1996).

\section{Intelligent Life Extending Control}

With the desire to reduce engine operating cost, the industry is interested in developing technologies that will allow the engine and its components to operate (remain on wing) longer, thus increasing the time between engine overhauls. How the engine is controlled has a significant impact on the life of the components. Typically, the propulsion system control design engineer attempts to get the maximum performance out of the system while maintaining safe operation. Recent studies have shown that small changes in engine operating parameters, such as turbine inlet temperature, can have a significant impact on the damage accrued by engine components while having little to no effect on engine performance. GRC developed the concept of Life Extending Control where the engine control system is designed to achieve the desired performance while minimizing the damage accrued in engine components, hence maximizing the usable engine life. The feasibility of this concept was demonstrated for the Space Shuttle Main Engine through simulation. Efforts in collaboration with industry led to the development of Intelligent Life Extending Control (ILEC) (Guo et al. 2004) for gas turbine engines with a focus on optimizing the engine acceleration schedule to minimize the damage accumulation in the hot-gas-path components, while meeting the Federal Aviation Administration (FAA) thrust response rise time requirement for PLA command from idle to maximum power.

During takeoff, when the pilot pushes the throttle to move the engine from idle to maximum power, the engine control generates a fuel flow command based on acceleration logic that ensures that the maximum thrust is achieved within a time limit based on FAA requirements. The engine components accumulate damage during this transient because of the quick and large changes in temperature and aerodynamic loads. By adjusting the acceleration logic such that the time to achieve maximum thrust is just within the FAA requirements, the temperature and load changes on the engine components can be kept to the minimum required to meet the performance. This will result in reduced damage accumulation for each takeoff and hence increase the amount of time the engine can stay on the aircraft before a major overhaul is required. The idea of ILEC is then to design a smart acceleration logic for engine control that will minimize the thermomechanical fatigue damage accumulated during a typical engine acceleration transient from idle to full power without any noticeable loss in engine performance. A typical baseline acceleration schedule for a commercial turbofan engine, as well as schedules optimized to achieve acceptable takeoff transients, while minimizing life consumption for a specific hot section engine component, are shown in Figure 9. The acceleration schedule is defined as the limit on the core speed rate of change as a function of the core speed (NH in Fig. 9). The thrust transients that correspond to these schedules are shown in Figure 10. In Figure 10, $T_{\text {rise }}$ is defined as the time for the thrust to reach 95 percent of the maximum power level. The optimized schedules were developed for $T_{\text {rise }}$ ranging from the value for the baseline schedule to the maximum allowable as per FAA certification requirements. Simulation results demonstrated that the optimized acceleration schedule decreased component life consumption during takeoff significantly for the same rise time, and extending the rise time slightly reduced the life consumption even more (Gou et al. 2004). 


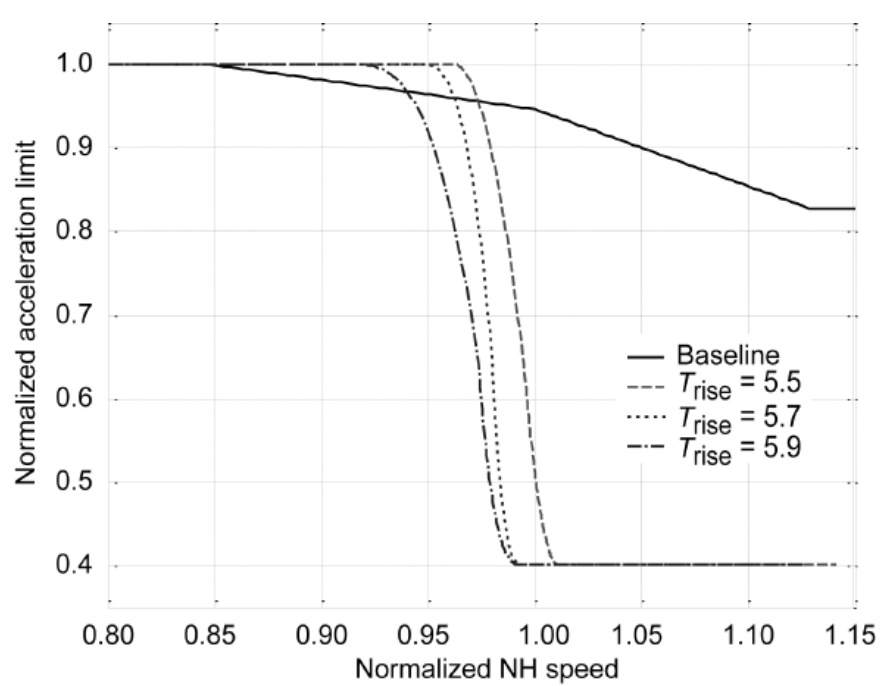

Figure 9.-Baseline and optimized acceleration schedules for takeoff acceleration process (from Guo et al. 2004; courtesy NASA); $T_{\text {rise }}$ is time for thrust to reach $95 \%$ of commanded thrust.

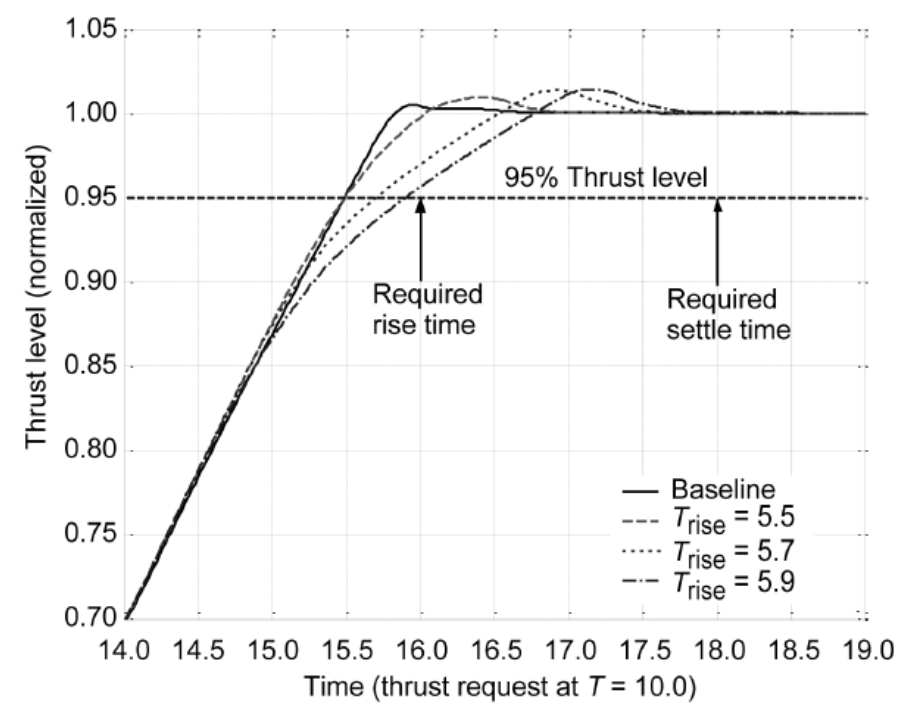

Figure 10.-Thrust response curves for the nominal and optimized acceleration schedule (from Guo et al. 2004; courtesy NASA): $T_{\text {rise }}$ is time for thrust to reach 95 percent of commanded thrust. 


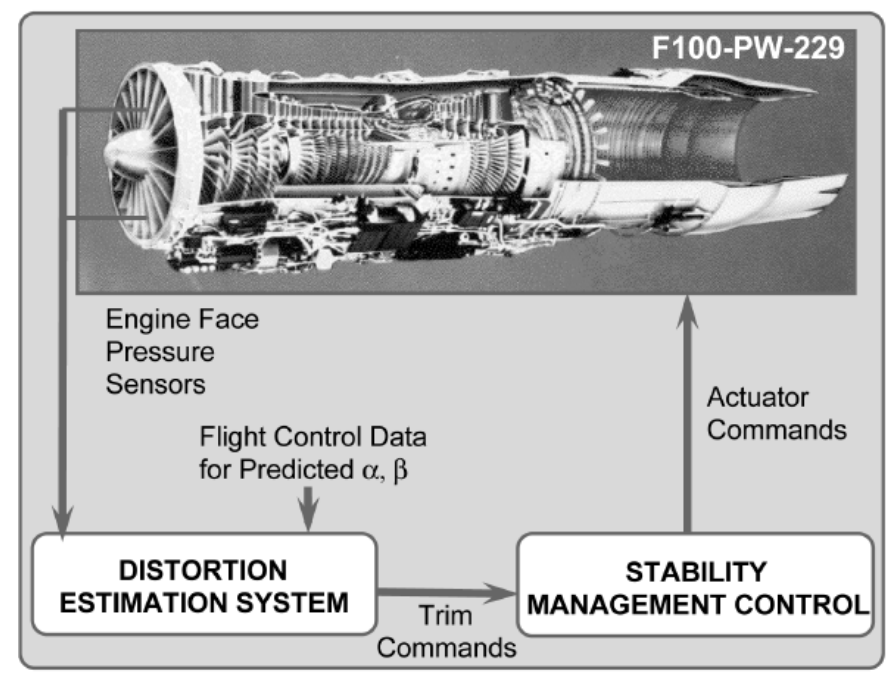

Figure 11.-Distortion tolerant control architecture developed under the HISTEC program (image courtesy of NASA).

\section{High Stability Engine Control (HISTEC)}

For aircraft engines, a safety margin, called the "stability margin," is built into the operation of the engine to prevent inception of fan/compressor stall due to inlet distortions caused by aircraft maneuvers or atmospheric disturbances. This stability margin results in a performance penalty being paid even at low distortion operating conditions such as cruise. Engine companies have estimated that being able to actively control the engine to safely maintain low stability margins under such low distortion operating conditions can result in reduction of 2 percent or more in specific fuel consumption.

GRC in partnership with PW, U.S. Air Force, McDonnell Douglas Aerospace, and DFRC developed and demonstrated technologies to allow for online active management of the engine stability margin. The distortion-tolerant control approach developed for the High Stability Engine Control (HISTEC) program (DeLaat et al. 1998) used a small number of engine-face pressure measurements combined with flight control data based predictions of angle of attack $(\alpha)$ and sideslip $(\beta)$ to accurately estimate the actual distortion present. From this pressure-based distortion estimate, an onboard stability audit generated a time-varying stall margin requirement. The engine controller (see Fig. 11) then accommodated the distortion by acting upon the current stall margin requirement supplied by the onboard stability audit. These technologies were demonstrated and evaluated in flight tests on a modified F-15 aircraft referred to as the Advanced Control Technologies for Integrated Vehicles (ACTIVE) aircraft. The flight demonstration was carried out in two parts: the first to show estimation and the second to show distortion accommodation. Postflight analysis showed that the HISTEC technologies were able to successfully estimate and accommodate distortion, transiently setting the stall margin requirement online and in real time. Flight demonstration of the HISTEC technologies significantly reduced the risk of transitioning these technologies to tactical and commercial aircraft engines.

\section{Active Stall Control}

The peak efficiency operating point of a turbine engine compressor is typically very near the compressor stall line as shown in Figure 12. In order to prevent catastrophic stall from occurring during large transients, the engine is operated with a sufficiently large safety margin. If the compressor can be safely operated closer to the designed compressor peak efficiency, then it will result in increased engine efficiency leading to significant savings in aircraft fuel costs. Even if compressor efficiency drops, cycle efficiency can be higher at higher overall pressure ratios. As shown in Figure 12, the compressor stall line 


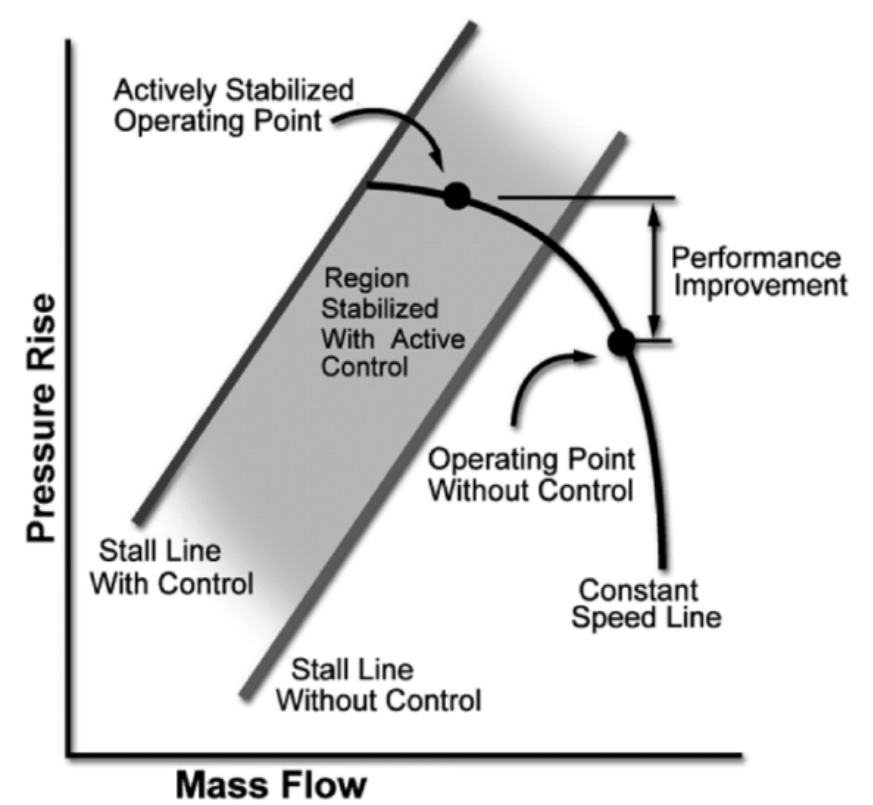

Figure 12.-Active stall control extends operating region for engines (image courtesy of NASA).

can be moved up through active control thus allowing safe operation at peak efficiencies. Note that the concept of active stall control differs from the distortion-tolerant control demonstrated under the HISTEC program. The distortion-tolerant control moves the engine operating line up or down using the variable geometry control effectors in the engine, such as the nozzle throat area in the F-15 ACTIVE aircraft demonstration, to adjust the stall margin. Under the active stall control concept, however, the engine stall line is moved up through some active flow control. The active stall control is obtained by sensing pressure changes at the inlet face of the compressor, which will indicate flow distortion that is the precursor to stall, and activating high bandwidth flow valves located around the circumference of the compressor that blow high-pressure air to counter the flow distortion before it builds up to stall.

The challenges for implementation of active stall control are developing accurate models of the stall phenomenon that can be used for control design, developing high-bandwidth (on the order of $500 \mathrm{~Hz}$ ) actuators for controlling flow valves, and understanding the effectiveness of different actuating schemes for stall control. The active stall control program at GRC was a cooperative program with industry and academia with strong participation from Massachusetts Institute of Technology (MIT). Active stall control was demonstrated in the laboratory environment at GRC for a single-stage high-speed compressor Weigl et al. 1998). One of the significant GRC contributions was in developing methods for early detection of stall precursors to enable timely application of the stall control (Bright et al. 1997). Experimental investigations were later completed in collaboration with industry under a program sponsored by the U.S. Air Force to demonstrate the technology on a multiple-stage compressor in the presence of inlet distortion. The effects of bleeding air from rear stages of the compressor for injection in the front stages was simulated during this experimental effort. These results indicated that substantial extension in safe operating range of the compressor can be achieved by active stall control technology.

\section{Current Research}

The CDB is currently conducting research in advanced engine control technologies under the Fundamental Aeronautics Program and the Aviation Safety Program in the NASA Aeronautics Research Mission Directorate. Some of the most significant current efforts are described below. An overview of all the current CDB research efforts is provided in Garg (2010), which includes additional references for the research areas not covered in this paper. 


\section{Model-Based Engine Control and Diagnostics}

So far the focus has primarily been on the engine control challenges without directly taking into consideration any information about the condition or health of the engine. Engine health monitoring can provide valuable information to enhance the engine control performance. The various on-wing health monitoring systems of today, which are a collection of separate, unrelated technologies, provide a basic level of monitoring. Their capabilities are relatively limited, and the information they provide is used mostly to initiate maintenance actions, not for real-time decision-making. One instance in which the information is used on wing is for sensor validation. The controller has some simple logic to perform checks of basic limit or rate of change on engine sensors and actuators. In some cases, on-board engine models are used in conjunction with the controller's own sensor voting scheme to help determine which sensor is correct when redundant sensors disagree. Whereas the current engine control architecture, as discussed in an earlier section, and the traditional diagnostic techniques are time tested and reliable, advanced techniques provide the promise to meet the challenging requirements of improved fuel efficiency, increased durability and life, decreased life cycle costs, and improved operations. The use of an onboard engine model to meet the challenging control and diagnostics requirements has emerged as the most viable approach. The continuing increase in computer processing capability has reached the point where the use of model-based algorithms for diagnostics and control of aircraft engines has become practical. Model-based technologies offer the potential for creating intelligent propulsion systemsdefined as self-diagnostic, self-prognostic, self-optimizing, mission-adaptable, and, inherently robustthat far exceed current systems in performance, reliability, and safety (Litt et al. 2004).

The concept of model-based engine control and diagnostics is shown in Figure 13. The onboard realtime engine model is driven with the engine control inputs and contains a tracking filter that uses the sensed measurements to update the health parameters in the engine model. The health parameters reflect the effects of engine degradation with usage and any gas path component faults. The outputs of the onboard model are the estimates of the sensed values and other performance parameters of interest. Transition to model-based control can occur in several ways. First, faults can be accommodated by changing the control laws, in a predetermined way, when a fault is detected. The changes are designed, at a minimum, to take the engine to a safe state, and preferably allow the engine to operate safely with the best, although probably degraded, performance. Secondly, the model allows the loop to be closed on unmeasured values (e.g., thrust, stall margin, etc.) for which there is no sensor (i.e., virtual sensors). Finally, in its most advanced form, the model is used directly in the control enabling the control to automatically adjust as the model adapts to the mission, deterioration, faults, weather, etc. Here the control can be designed to maximize performance without excessive conservatism.

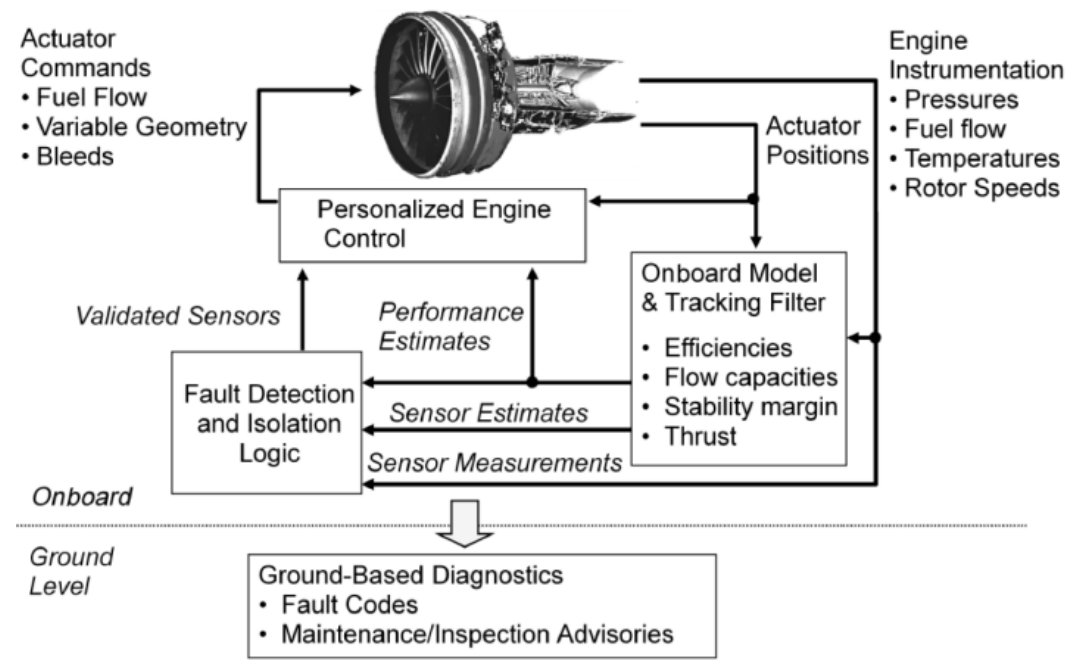

Figure 13.-Model-based engine control and diagnostics architecture (image courtesy of NASA). 
Adibhatla and Lewis (1997) provides an excellent example application of model-based control to aircraft engines. However, as discovered during the early research on model-based engine control, one of the challenges in engine application is that the number of health parameters to be estimated generally exceeds the number of sensors available for the tracking filter design, which poses an underdetermined estimation problem. A common approach to address this shortcoming is to estimate a subset of the health parameters, referred to as "model tuning parameters." Although this approach enables the Kalman filter to tune the onboard model so that its outputs track measured (sensed) engine outputs, there can be significant error in estimation of unmeasured engine outputs because the impact of the entire set of health parameters will not be accurately represented within the Kalman filter model.

Recently an innovative methodology (Simon and Garg 2010) has been developed at GRC that creates a tuning parameter vector defined as a linear combination of all health parameters and of appropriate dimension to enable Kalman filter estimation. Selection of this tuning parameter vector is performed using a multivariable iterative search routine that minimizes the theoretical mean-squared estimation error in the parameters of interest. The new methodology was validated in simulation using an aircraft turbofan engine model. The simulation results demonstrated that applying the enhanced tuning parameter selection methodology resulted in a significant reduction in average estimation error compared to the conventional approach of selecting a subset of health parameters as tuners. Figure 14 shows a comparison of engine thrust estimates from an engine model using the conventional approach of selecting a subset of health parameters for tuning the onboard model versus the recently developed optimal tuner selection approach. With the optimal tuner selection approach, both the variance and the steady-state error in the thrust estimation are significantly reduced.

With the optimal tuner selection approach developed in (Simon and Garg 2010), sufficient estimation accuracy of the unmeasured variables can be obtained to allow for implementation of direct control of thrust and stall margins using the model estimated value. Research on this application is currently ongoing at GRC. Figure 15 shows a preliminary result from this research. The optimal tuner approach was applied to the simulation of a modern commercial high bypass turbofan engine. Response of the engine from throttle input to thrust was compared for the baseline case of controlling the (EPR) using measured pressures versus closing the loop on the estimated thrust for direct thrust control. In Figure 15, the dashed line shows the bounds for thrust response with the EPR control as the engine degrades with usage. With direct thrust control, the thrust response is maintained within a very tight bound regardless of the engine condition.

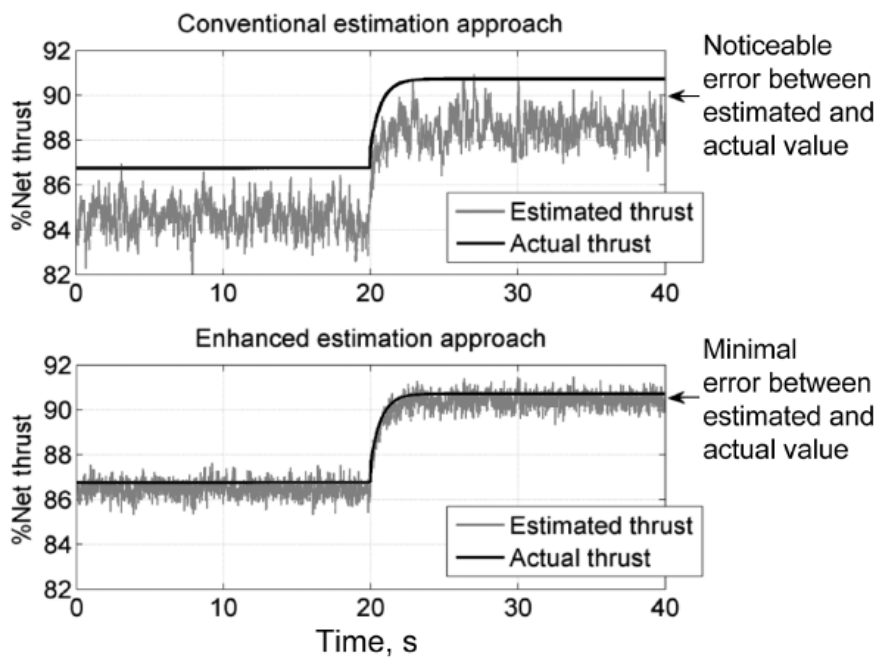

Figure 14.-Thrust estimation accuracy comparison-conventional versus enhanced (optimal) tuning parameter selection (image courtesy of NASA). 


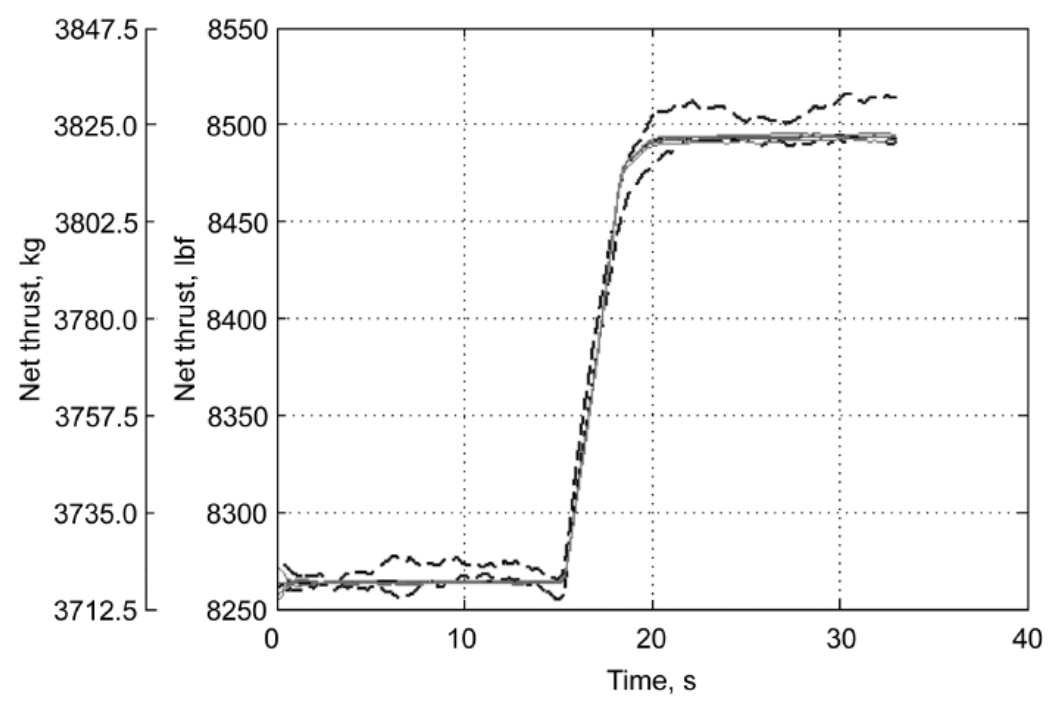

Figure 15.-Thrust response comparison-EPR control versus direct thrust control (image courtesy of NASA).

The optimal-tuner-based onboard modeling approach has also proven to be extremely useful for gas path diagnostics. A full envelope self-tuning model for a typical commercial aircraft type engine simulation has been developed as documented in Simon et al. (2011). A technique for selecting a single globally optimal set of tuners applicable throughout an engine's operating envelope has been demonstrated. This is necessary to enable interpolation between operating points within a piecewise linear design implementation. Theoretical evaluation results using an aircraft engine model showed that the application of a single globally optimal set of tuners results in only a slight increase in estimation errors for parameters of interest over using a set of tuners that are optimal for a particular operating point. The methodology developed in Simon et al. (2011) also takes into account the closed-loop operation of the engine. Most recently, a Kalman-filter-based approach for integrated online aircraft engine performance estimation and gas path fault diagnostics has been developed using the optimal tuner approach (Simon and Armstrong 2012). The Kalman filter is designed to estimate the vector of tuning parameters, appropriately sized to enable estimation. The estimated tuning parameters are then transformed into a larger vector of health parameters representing system performance deterioration and fault effects. The results of this study showed that basing fault isolation decisions solely on the estimated health parameter vector does not provide ideal results. Furthermore, expanding the number of the health parameters to address additional gas path faults causes a decrease in the estimation accuracy of those health parameters representative of turbomachinery performance deterioration. However, improved fault isolation performance was demonstrated through direct analysis of the estimated tuning parameters produced by the Kalman filter. This was found to provide equivalent or superior accuracy compared to the conventional fault isolation approach based on the analysis of sensed engine outputs, while also simplifying online implementation requirements. Results from the application of these techniques to an aircraft engine simulation are presented and discussed in Simon and Armstrong (2012).

\section{Engine Dynamic Models for Control and Diagnostics Technology Development}

Development and validation of the various controls and diagnostics technologies discussed so far requires the availability of a transient engine simulation representing the dynamic behavior of the engine. Typically, the engine simulation cycle decks developed by industry are proprietary in nature and are not available for NASA to share with universities or small businesses conducting controls research. NASA has developed the Numerical Propulsion Simulation System (NPSS), which has now become the default simulation system being used by the aerospace industry. However, the NPSS system is geared more 
towards doing cycle analysis or detailed engine component design and is not "user-friendly" for controls research. To overcome these shortcomings and meet the need of the engine controls and diagnostics researchers to have realistic engine simulation platforms to evaluate their ideas and concepts, the CDB started an effort in the early 2000s to develop dynamic engine simulations in the Matlab/Simulink environment that could be made publicly available without any industry proprietary issues.

In 2003, GRC released the Modular Aero-Propulsion System Simulation (MAPSS) software (Parker and Guo 2003), which provides a model of a conceptual advanced military turbofan engine with a research-type controller. The MAPSS code was made available through the GRC software repository and was downloaded by many researchers. Building on the success of MAPSS, CDB developed the Commercial Modular Aero-Propulsion Simulation (C-MAPSS) software code representing a commercial 40,823 kg-f (90,000 lbf) thrust engine, originally modeled in NPSS. The C-MAPSS simulation (DeCastro et al. 2008) included an extensive graphical user interface (GUI) capability, offering the capability to generate linear models, design controllers using the KQ (or Edmunds) model-matching approach, and perform closed-loop system evaluations. The C-MAPSS was also the first publicly available (limited to U.S. citizens because of International Traffic in Arms Regulations (ITAR) restrictions) dynamic engine simulation with a realistic control logic representative of what is currently flying on modern commercial aircraft engines. The discussion and the results shown in the earlier section on the "State of the Art Engine Control" are based on the C-MAPSS simulation.

Most recently, CDB has developed the C-MAPSS40k software package, which is a high-fidelity dynamic simulation of a generic 18,142 kg-f (40,000 lbf) thrust class commercial engine with a representative controller (May et al. 2010). Flight test data collected from a highly instrumented engine was used to provide realism in the C-MAPSS40k model engine performance. This engine simulation was created especially for the development and evaluation of control strategies to use the engine as a flight control effector during emergencies. C-MAPSS40k incorporated a number of new features including an iterative solver and detailed compressor stall models. The iterative engine solver enforces mass flow balance through the engine at every time step. This feature produces a realistic simulation while allowing the user the ability to configure the solver for the specific test, such as small throttle steps, and still maintain faster-than-real-time operation. The detailed compressor stall models include the compressor map stall line as well as a number of stall margin debits such as stall line change due to engine deterioration, stall margin change due to rotor tip clearance changes, and the transient debit due to heat transfer between the mass flow and rotor blades and compressor casing. The inclusion of these debits allows control developers to have a good estimate of the required stall margin stack-up by eliminating some of the uncertainty. C-MAPSS40k also includes an "industry standard" controller for use as a baseline against which to compare new controllers and architectures. This baseline controller follows the most common design principles in current commercial engine controllers and produces realistic transient behavior at conditions across the complete engine flight envelope. With these capabilities, users in academia, industry, and government have access to a generic, high-fidelity engine simulation that can be used to quickly develop, simulate, and test new control system components and architectures and diagnostic algorithms. The C-MAPSS40k simulation is being used extensively in NASA-sponsored research programs under the Aviation Safety Program and the Fundamental Aeronautics Program and has been downloaded by multiple organizations including academia and industry.

\section{Distributed Engine Control}

Presently, engine control system architecture is based on a centralized design in which discrete sensors and effectors are directly wired to a single engine-mounted electronics package (see Fig. 16). This avionics unit, called the FADEC or ECU contains all the necessary circuitry to properly interface with engine control devices as well as cockpit command and data communications. The major driving factor for centralized engine control architecture is that commercially available electronics cannot withstand the high operating temperatures around the engine. Putting all the electronics needed for sensor signal processing, actuator loop closures, control law processing, etc., in one box, which is hardened to 


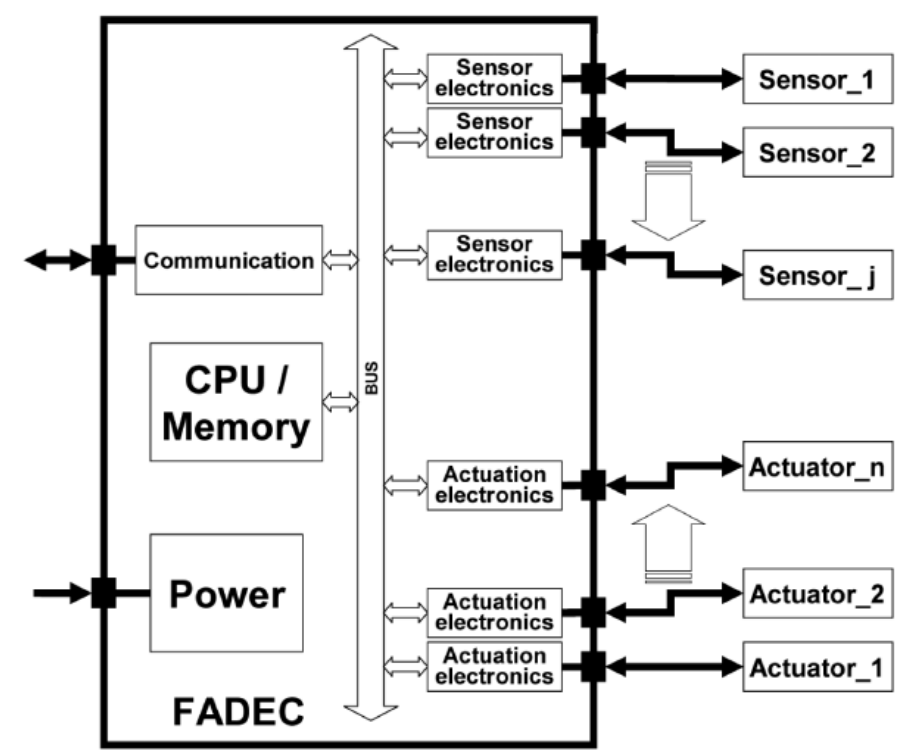

Figure 16.-Centralized engine control architecture: $\mathrm{CPU}$ is central processing unit (image courtesy of NASA).

withstand the harsh engine operating environment (high pressures and vibrations) and also provides means of cooling the electronics, has emerged as the most weight-efficient approach to implement digital engine control. For commercial engines, the FADEC is placed on the fan casing and is air cooled; for military engines, the FADEC is placed on the casing of the gas generator and is fuel cooled.

The centralized control architecture imposes many constraints which limit the opportunities to introduce new control capabilities and also add to the engine life cycle cost. The first issue is that of electronics obsolescence management. Typically a FADEC design is expected to operate over a long period of time since any changes in the FADEC design require recertification of the whole engine control system. A number of the electronic components, especially those associated with control law processing and communications are subject to rapid obsolescence, driven by a high turn-over rate for the consumer electronics. Adequate inventories of these components have to be maintained to last over the FADEC design life time. Second, the sensors and actuators are connected to FADEC through a bundle of wires that need to be routed around the rotating machinery, resulting in multiple connectors. The wiring bundle not only adds weight, but also the multitude of connectors poses reliability issues. The FADEC design is highly individualized for a specific engine, and the lack of modularity prevents the opportunity for reducing costs. Finally, the size of the FADEC itself poses a problem for the engine configurations such as the geared turbofan (GTF) and open rotor that are emerging to meet the challenges of increased fuel efficiency and reduced emissions. The large fan on the GTF poses challenges for accommodating the current size FADECs on the fan casing - both from the perspective of keeping the engine frontal area to the lowest possible to reduce drag and incurring weight penalties on the fan casing for the structural strengthening required for the FADEC. For open rotor configurations, the FADEC will need to be placed on the gas generator casing, which is a much harsher environment and will result in weight penalties associated with further ruggedizing of the FADEC and the need to provide fuel cooling.

To keep the engine control architecture from being a limiting factor in the realization of technologies that enable highly efficient engines with low life cycle costs, there is extensive interest among the aeropropulsion industry to develop technologies that will enable a distributed engine control (DEC) architecture. In a DEC system architecture, as shown in Figure 17, any number of control elements are tied together through a common, standardized communication interface. Sensors and effectors are replaced by control nodes which may provide sensor data, operate actuators, or perform combinations of both. The massive wiring harness, which previously tied together the control element to interface circuitry in the engine-mounted avionics package, is replaced by a simple but robust digital communication structure. 


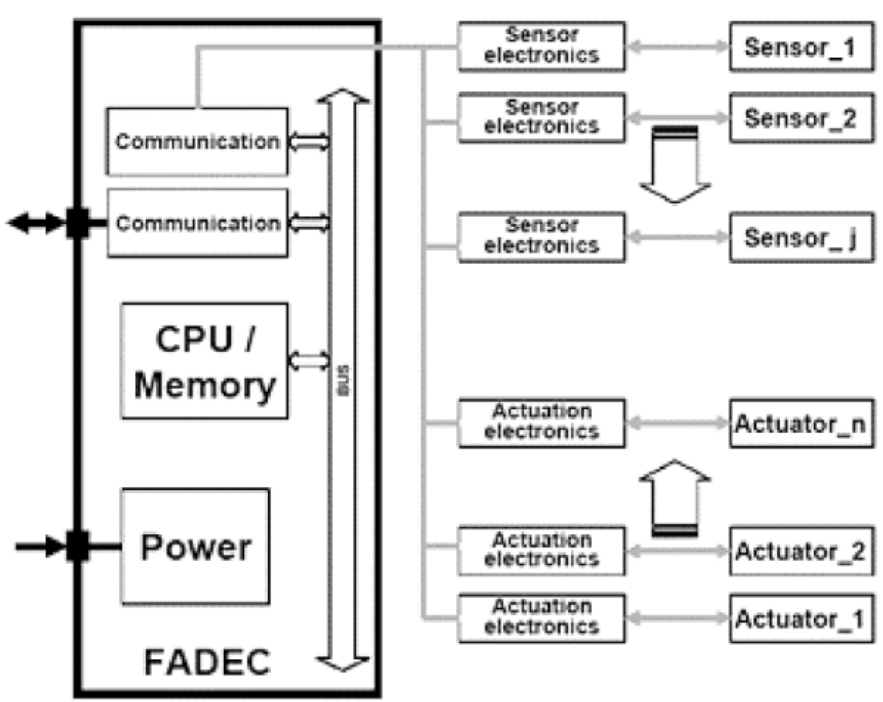

Figure 17.-Distributed engine control architecture (image courtesy of NASA).

Potential benefits of DEC include reduced control system weight, improved reliability, reduced operating cost, reuse for multiple applications, and flexibility to add new capability. Additionally, DEC is critical to integrate active component control technology with the overall engine system control.

The CDB is working in collaboration with AFRL, the aeropropulsion industry, and major providers of FADEC technology by way of the Distributed Engine Control Working Group (DECWG) to help identify the key challenges for enabling DEC and provide directions for overall research. This partnership is essential for leveraging a common interest in developing precompetitive controls technologies, establishing standards for continued collaboration, and identifying requirements for electronics. Working in collaboration with the DECWG, NASA has developed a roadmap for maturing critical technologies to move the engine control architecture from the current centralized to a future fully distributed one (Culley 2010). Apart from developing the technologies to enable distributed engine control, it will also be important to develop a hardware-in-the-loop facility that can be used to test and investigate integration aspects of various components of the distributed control. GRC currently has a contracted effort in place with an engine manufacturer, which will develop such a capability and have it available at GRC by late 2014 .

\section{Active Combustion Control}

As the aircraft engine industry moves towards lean-burning combustors in order to meet stringent low-emissions requirements, maintaining stability for these combustors can become problematic. The thermoacoustic combustion instability issues have already been encountered in lean-burning groundbased power generation gas turbine systems. For ground-based systems, these issues have been overcome by making ad-hoc design changes or by applying active control. However, dealing with these issues in aeroengines is more challenging since aeroengines operate over a wide range of conditions. In early 2003, GRC started working in collaboration with PW and United Technologies Research Center (UTRC) to develop and demonstrate technologies for the active suppression of thermoacoustic instability. As part of this effort, a single-nozzle combustor rig was developed at UTRC which had the capability to duplicate the thermoacoustic instability observed in an actual engine test and also to exhibit a larger amplitude, lower frequency instability. In order to suppress instabilities, it is necessary to modulate the fuel flow entering this representative combustor at roughly $500 \mathrm{~Hz}$ (instability frequency, which is a function of combustor length). A valve was developed in conjunction with Georgia Institute of Technology, which is capable of generating the required high-frequency modulations in fuel flow. An actuator characterization rig was built up at GRC to be able to identify the dynamic characteristics of the valve so that resulting actuator models can be used for control design development. 
In order to achieve closed-loop suppression of the combustion instability, two alternative control methods were developed (Kopasakis et al. 2004; Le et al. 2005). These control methods were formulated to deal with the large wideband combustor noise, severe time delay, and randomness in phase associated with the combustor thermoacoustic pressure oscillations. Both controllers use the sensed combustion pressure as input and fuel modulations as output. Both control methods were initially evaluated against reduced-order oscillator models of the combustor pressure in order to verify basic functionality. To provide better fidelity validation of controller performance prior to rig testing, both controllers were then tested against a sectored one-dimensional (1D) model of the combustor rig. The controllers were evaluated on the NASA combustor rig at UTRC and at GRC, and they demonstrated significant reduction in instability magnitude for both the high-frequency $(\sim 500 \mathrm{~Hz})$ engine-like instability and the lower frequency $(\sim 300 \mathrm{~Hz})$ large-amplitude instability. This was the first time such instability suppression had been demonstrated in an aeroengine-like environment.

GRC has continued to investigate the capability to suppress thermoacoustic instabilities in advanced ultra-low-emissions combustors being designed by NASA and the aerospace industry. Key to the success of this effort are simulations that can capture the instability behavior of these advanced combustors. A simulation has been developed, which captures the thermoacoustic instability behavior of an advanced, low-emissions combustor prototype that was being tested for emissions performance in a rig at GRC. During testing, the combustor exhibited thermoacoustic instabilities that are related to increasing fuel flow and that potentially prevent full-power operation. Comparison of the advanced, low-emissions combustor rig experimental data and the simulation data showed that the simulation captures the essentials of the dynamic behavior of the rig (DeLaat and Paxson 2008). Utilizing this simulation, the NASA Adaptive Sliding Phasor Average Control (ASPAC) instability control method was updated for the low-emissions combustor prototype. Active combustion instability suppression using the ASPAC control method has recently been demonstrated experimentally with this combustor prototype in a NASA combustion test cell operating at engine pressures, temperatures, and flows (DeLaat et al. 2012). Successful instability suppression was shown using a dynamic pressure sensor in the combustor with controller feedback driving a high-frequency fuel valve to perturb the combustor fuel flow. It was also demonstrated that the controller can prevent the instability from occurring while combustor operation is transitioning from a stable, low-power condition to a normally unstable high-power condition, thus enabling the high-power condition. Figure 18 shows some of the results discussed in DeLaat et al. (2012).
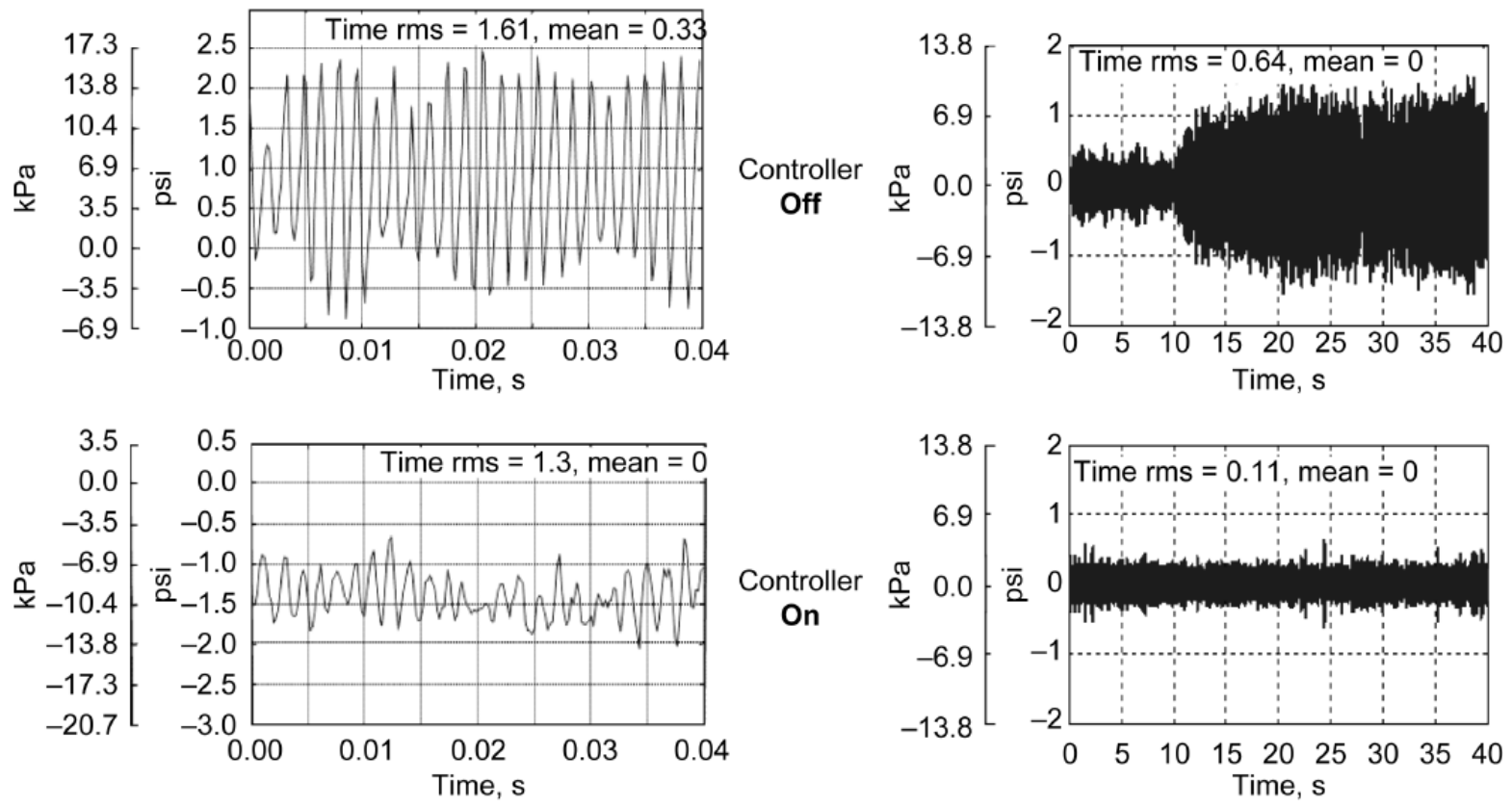

Figure 18.-Thermoacoustic instability suppression and prevention with GRC-developed combustion control (image courtesy of NASA). 
The two sets of results show the pressure with and without the controller being on. For the plots on the left, the top plot shows the pressure oscillations at a particular set point; the bottom plot with the controller on shows that the pressure oscillations are suppressed significantly and the pressure variation is within the noise level. For the plots on the right, the top plot shows that pressure oscillations grow in magnitude as the engine is throttled up (fuel flow is increased to the combustor); the bottom plot shows that with the controller on, the instability can be prevented from occurring as the engine is throttled up. These results are very promising in demonstrating the capability of GRC-developed combustion control techniques to enable safe operation of ultra-low-emissions combustors throughout the operating envelope. Research is currently ongoing to develop fuel actuation systems that can be used with the emerging industry and NASA ultra-low-emissions combustor concepts.

\section{High-Speed Propulsion System Dynamic Modeling and Control}

The CDB is developing dynamic modeling and control methods for high-speed propulsion systems to support the objectives of the Supersonic (SUP) and Hypersonic (HYP) projects of the NASA

Fundamental Aeronautics Program. For the supersonic propulsion system area, the objective is to develop the models and design the controls so that the inlet and engine perform as desired, especially as the inlet is the most crucial component of a supersonic engine. The integrated inlet/engine control design should be able to suppress upstream flow disturbances such as those due to atmospheric wind gusts, aircraft maneuver, as well as flexible mode excitation from the slender body aircraft structure. The propulsion and integrated engine and aero-servo-elastic structure should not produce thrust variations that impact ride quality and aircraft stability. The CDB approach is to develop high-fidelity propulsion system models (1D computational fluid dynamics (CFD) for the inlet and stage-by-stage volume dynamics for the engine) that can be used for controls methodology development and application. To date, both a turbojet and a turbofan engine have been modeled, control designs and schedules have been developed to operate the engine throughout its expected operating envelope, atmospheric turbulence models have been developed, and a quasi-1D CFD supersonic inlet model has been developed for internal compression inlets. Also, an innovative loop shaping feedback controls design methodology has been developed that maximizes system performance based on hardware capability. This controls approach has been applied to design engine speed control as well as inlet shock position controls in the presence of atmospheric disturbances (Kopasakis and Connolly 2009). Research is ongoing in developing a dynamic model of the $\mathrm{N}+3$ propulsion system configuration that has been established as the baseline for the SUP project.

For the HYP project, the CDB effort has focused on developing dynamic models and tools to aid the design of control algorithms to manage a turbine-based combined cycle (TBCC) airbreathing propulsion system during the critical operating period when the propulsion system transitions from one cycle to another, "referred to as mode transition." The TBCC consists of a dual flow path: a low-speed flow path with a turbine engine to accelerate to supersonic speeds and a high-speed flow path with a scramjet to accelerate to and maintain hypersonic speeds. During the mode transition, the control challenge is to maintain the shock position for the low-speed flow path in such a way as to maintain the required flow for an orderly safe shut-down of the turbine engine. Current research is focused on developing the computational models to simulate an airbreathing TBCC propulsion system inlet. The TBCC inlet aerodynamic design being modeled is that of the Combined-Cycle Engine (CCE) Testbed. The CCE testbed is a large-scale hardware model of an aerodynamic design that was verified in a small-scale screening experiment. The CCE testbed has been designed for experiments in the GRC 10- by 10-Foot Supersonic Wind Tunnel (SWT). This mixed compression inlet system is suitable for experiments focusing on mode transition studies. The modeling approach includes employing existing state-of-the-art simulation codes, developing new dynamic simulations, and performing system identification experiments on the CCE testbed in the SWT (Stueber et al. 2010). The system identification experiments were recently completed, and the extensive amount of data collected is currently being analyzed. The original research plan was to develop inlet control logic using the dynamic models based on the system 
identification data, and then test the control on the CCE testbed in the SWT. However, future testing on the CCE testbed has been cancelled due to funding cuts in the HYP project. The current plan is to demonstrate the control logic in a simulation of the CCE propulsion system, which will include updated inlet model from the experimental data.

\section{Rocket Engine Control}

Because of space limitations, this paper has focused on the aircraft engine control work done by the controls group at GRC. This group has also been active in the area of rocket engine dynamic modeling and control and has made various significant contributions. These contributions include the theory to understand and thus avoid rocket engine chugging. This theory was applied to stabilize the Lunar Lander engine. Also hot-firing studies of the Centaur vehicle in the Plum Brook B-2 altitude test chamber were used to determine the feed-line dynamics to assure POGO stability of that vehicle. POGO instability refers to a coupling between the fuel flow feed-lines and the thrust generated by the rocket which results in a pogo like behavior for the rocket due to thrust oscillations. Further studies, in the 1970s, supplied advanced technology for possible active POGO suppression on the Space Shuttle Main Engine. The concept of life-extending control was initially developed for rocket engines (Lorenzo et al. 1992) and then applied to aircraft engines as discussed in an earlier section. In the late 1980s to mid-1990s extensive work was done on applying emerging health management technologies to the Space Shuttle Main Engine (Duyar et al. 1992). The CDB is continuing the technology development effort in support of the current NASA Human Exploration program through development of fault management technologies as described in Melcher (2011).

\section{Conclusion}

In conclusion, this paper provided a broad overview of the state-of-the-art of engine control, some significant past contributions of the controls group at the NASA Glenn Research Center (GRC) that have resulted in increased efficiency and performance of aircraft engines, and some recent accomplishments where elements of the technologies developed can be expected to find their way into future aircraft engines. The Controls and Dynamics Branch (CDB) continues to perform cutting-edge engine control and diagnostics research to meet the challenging goals of the NASA Fundamental Aeronautics Program and the Aviation Safety Program. From a control logic perspective, the CDB is leading research in modelbased engine control and diagnostics, which will enable highly efficient and reliable operation of future engines. From a control architecture perspective, the CDB is leading research to enable transition from the current centralized control architecture to a future distributed engine control architecture, which will provide increased modularity, capability to incorporate new control component technologies as these mature, and reduced life cycle cost. The CDB is also leading research in developing active component control technologies, such as active combustion control, which are critical to realizing the benefits of high-efficiency components with safe operation throughout the flight envelope.

\section{References}

Adibhatla, S., and Lewis, T. (1997). "Model-based intelligent digital engine control (MoBIDEC).” 97-3192, AIAA, Reston, VA.

Bright, M. M., et al. (1994). "Piloted evaluation of an integrated methodology for propulsion and airframe control design.” 94-3612, AIAA, Reston, VA.

Bright, M. M., et al. (1997). "Stall precursor identification in high-speed compressor stages using chaotic time series analysis methods.” J. Turbomach., 119(3), 491-499.

Burcham, F. W., et al. (1984). "Digital engine electronic control (DEEC) flight evaluation in an F-15 airplane.” CP-2298, NASA, Edwards, CA, <http://ntrs.nasa.gov/> 
Culley, D. E. (2010). “Transition in gas turbine control system architecture: modular, distributed and embedded.” GT2010-23226, ASME, New York, NY.

DeCastro, J. A., Litt, J. S., and Frederick, D. K. (2008). “A modular aero-propulsion system simulation of a large commercial aircraft engine,” 2008-4579, American Institute of Aeronautics and Astronautics (AIAA), Reston, VA.

DeHoff, R. L., et al. (1977). "F100 Multivariable Control Synthesis Program-Volume I: Development of F100 Control System.” TR-77-35, Air Force Aero Propulsion Laboratory (AFAPL), WrightPatterson Air Force Base, OH.

DeLaat, J. C., Southwick, R. D., Gallops, G. W., and Orme, J. S. (1998). "High stability engine control (HISTEC): flight demonstration results.” Technical Paper 985556, SAE International, Warrendale, PA.

DeLaat, J. C., and Paxson, D. E. (2008). "Characterization and simulation of the thermoacoustic instability behavior of an advanced, low emissions combustor prototype.” 2008-4878, AIAA, Reston, VA.

DeLaat, J. C., Kopasakis, G., Saus, J. R., and Chang, C. T. (2012). “Active combustion control for aircraft gas-turbine engines-experimental results for an advanced, low-emissions combustor prototype.” 2012-0783, AIAA, Reston, VA.

Duyar, A., Guo, T.-H., Merrill, W.C., and Musgrave, J. (1992). "Implementation of a model based fault detection and diagnosis for actuation faults of the space shuttle main engine.” TM-105781, NASA, Cleveland, $\mathrm{OH},<$ http://ntrs.nasa.gov/>

Frederick, D., Garg, S., and Adibhatla, S. (1996). “Turbofan engine control design using robust multivariable control technologies.” 96-2587, AIAA, Reston, VA.

Garg, S., Ouzts, P. J., Lorenzo, C. F., and Mattern, D. L. (1991). "IMPAC—an integrated methodology for propulsion and airframe control.” American Control Conference, Boston, MA.

Garg, S., and Mattern, D. L. (1994). "Application of an integrated methodology for propulsion and airframe control design to a STOVL aircraft.” 94-3611, AIAA, Reston, VA.

Garg, S. (2010). "Propulsion controls and diagnostics research in support of NASA Aeronautics and Exploration Mission programs.” 2010-6747, AIAA, Reston, VA.

Garvin, R. V., (1998). "Starting something big - the commercial emergence of GE aircraft engines." AIAA, Reston, VA.

Guo, T. -H., Chen, P., and Jaw, L. (2004). “Intelligent life-extending controls for aircraft engines.” 20046468, AIAA, Reston, VA.

Jaw, L. C., and Garg, S. (2003). "Propulsion control technology development in the U.S.-A historical perspective.” 2003-1073, International Symposium on Air-Breathing Engines (ISABE), Cincinnati, $\mathrm{OH}$.

Jaw, L. C., and Mattingly, J. D. (2009). “Aircraft engine controls: design, system analysis and health monitoring.” AIAA Education Series, Reston, VA.

Ketchum, J. R., and Craig, R. T. (1952). "Simulation of linearized dynamics of gas-turbine engines." TN-2826, NACA, Cleveland, OH, <http://ntrs.nasa.gov/>

Kopasakis, G., DeLaat, J. C., Chang, C. T. (2004). "Validation of an adaptive combustion instability control method for gas-turbine engines.” 2004-4028, AIAA, Reston, VA.

Kopasakis, G., and Connolly, J., (2009). "Shock positioning controls design for a supersonic inlet.” 45th Joint Propulsion Conference \& Exhibit, Denver, CO.

Le, D. K., DeLaat, J. C., Chang, C. T., and Vrnak, D. R. (2005). "Model-based self-tuning multiscale method for combustion control.” 2005-3593, AIAA, Reston, VA.

Lehtinen, B., DeHoff, R. L., and Hackney, R. D. (1979). "Multivariable control altitude demonstration on the F100 turbofan engine.” 79-1204, AIAA, Reston, VA.

Litt, J. S., et al. (2004). "A survey of intelligent control and health management technologies for aircraft propulsion systems.” AIAA Journal of Aerospace Computing, Information and Communication, 1.

Lorenzo, C. F., et al. (1992). "Life extending control for rocket engines.” TM-105789, NASA, Cleveland, $\mathrm{OH},<$ http://ntrs.nasa.gov/> 
Mattern, D. L., and Garg, S. (1992). "Propulsion system performance resulting from an integrated flight/propulsion control design.” 1992-4602, AIAA, Reston, VA.

Mattingly, J. D. (1996). "Elements of Gas Turbine Propulsion.” McGraw-Hill, New York, NY.

May, R. D., Csank, J. T., Lavelle, T. M., Litt, J. S., and Guo, T. -H., (2010). “A high-fidelity simulation of a generic commercial aircraft engine and controller.” Joint Propulsion Conference, Nashville, TN.

Melcher, K. (2011). "Optimal sensor selection and testability analysis technologies for fault management.” Presentation at the Commercial and Government Responsive Access to Space Technology Exchange (CRASTE), Atlanta, GA.

Merrill, W. C., DeLaat, J. C., Kroszkewicz, S. M., and Abdelwahab, M. (1987). "Full-scale engine demonstration of an advanced sensor failure detection, isolation, and accommodation algorithmPreliminary results.” 87-2259, AIAA, Reston, VA.

Merrill, W. C., DeLaat, J. C., and Burton, W. (1988). "Advanced detection, isolation, and accommodation of sensor failures-Real-time evaluation.” AIAA Journal of Guidance, Control and Dynamics, 11(6), 517-526.

Otto, E. W., and Taylor, B. L., III, (1950). "Dynamics of a turbojet engine considered as a quasi-static system.” NACA Report 1011, NACA, Washington, DC, <http://ntrs.nasa.gov/>

Parker, K., and Guo, T. (2003). "Development of a turbofan engine simulation in a graphical simulation environment.” TM-2003-212543, NASA, Cleveland, OH, <http://ntrs.nasa.gov/>

Polley, J. A., Adibhatla, S., and Hoffman, P. J. (1988). "Multivariable turbofan control for full flight envelope operation.” 88-GT-6, ASME, New York, NY.

Shaw, P. D., Rock, S. M., and Fisk, W. S. (1988). "Design methods for integrated control systems." TR-88-2061, AFWAL, Wright-Patterson Air Force Base, OH.

Simon, D. L., and Garg, S. (2010). “Optimal tuner selection for Kalman filter-based aircraft engine performance estimation.” ASME Journal of Engineering for Gas Turbines and Power, 132(3).

Simon, D. L., Armstrong, J. B., and Garg, S. (2011). "Application of an optimal tuner selection approach for on-board self-tuning engine models.” GT-2011-46408, ASME, New York, NY.

Simon, D. L., and Armstrong, J. B. (2012). "An integrated approach for aircraft engine performance estimation and fault diagnostics.” GT-2012-69905, ASME, New York, NY.

Small, L. L. (1982). “AFWAL turbine engine controls research and development-Present and future.” AIAA 20th Aerospace Sciences Meeting, Los Angeles, CA.

Smith, K. L. (1986). “Design methods for integrated control systems.” TR-86-2103, AFWAL, WrightPatterson Air Force Base, $\mathrm{OH}$.

Spang, H. A., III, and Brown, H. (1999). “Control of jet engines.” Control Engineering Practice, 7, 10431059.

Stueber, T. J., Vrnak, D. R., Le, D. K., and Ouzts, P. J., (2010). “Control activity in support of NASA TBCC research.” TM-2010-216109, NASA, Cleveland, OH, <http://ntrs.nasa.gov/>

Szuch, J. R., et al. (1977). "F100 multivariable control synthesis program—Evaluation of multivariable control using a real-time engine simulation.” TP-1056, NASA, Cleveland, OH, $<$ http://ntrs.nasa.gov/>

Urban, L. A., (1974). "Parameter selection for multiple fault diagnostics of gas turbine engines." 74-GT62, American Society of Mechanical Engineers (ASME), New York, NY.

Watts, S. R., and Garg, S. (1995). "A comparison of multivariable control design techniques for a turbofan engine control.” ASME 40th Gas Turbine and Aeroengine Congress and Exposition, Houston, TX.

Weigl, H. J., et al. (1998). "Active stabilization of rotating stall and surge in a transonic single stage axial compressor.” J. Turbomach., 120(4), 625-636. 


\begin{tabular}{|c|c|c|c|c|c|}
\hline \multicolumn{5}{|c|}{ REPORT DOCUMENTATION PAGE } & $\begin{array}{c}\text { Form Approved } \\
\text { OMB No. 0704-0188 }\end{array}$ \\
\hline \multicolumn{6}{|c|}{ 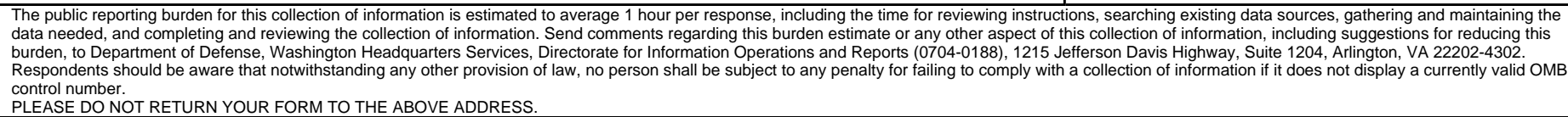 } \\
\hline \multicolumn{2}{|c|}{$\begin{array}{l}\text { 1. REPORT DATE }(D D-M M-Y Y Y Y) \\
01-04-2013\end{array}$} & \multicolumn{3}{|c|}{$\begin{array}{l}\text { 2. REPORT TYPE } \\
\text { Technical Memorandum }\end{array}$} & 3. DATES COVERED (From - To) \\
\hline \multirow{3}{*}{\multicolumn{5}{|c|}{$\begin{array}{l}\text { 4. TITLE AND SUBTITLE } \\
\text { Aircraft Turbine Engine Control Research at NASA Glenn Research Center }\end{array}$}} & 5a. CONTRACT NUMBER \\
\hline & & & & & 5b. GRANT NUMBER \\
\hline & & & & & 5c. PROGRAM ELEMENT NUMBER \\
\hline \multirow{3}{*}{\multicolumn{5}{|c|}{$\begin{array}{l}\text { 6. AUTHOR(S) } \\
\text { Garg, Sanjay }\end{array}$}} & 5d. PROJECT NUMBER \\
\hline & & & & & 5e. TASK NUMBER \\
\hline & & & & & $\begin{array}{l}\text { 5f. WORK UNIT NUMBER } \\
\text { WBS 432938.11.01.03.02.02.15 }\end{array}$ \\
\hline \multicolumn{5}{|c|}{$\begin{array}{l}\text { 7. PERFORMING ORGANIZATION NAME(S) AND ADDRESS(ES) } \\
\text { National Aeronautics and Space Administration } \\
\text { John H. Glenn Research Center at Lewis Field } \\
\text { Cleveland, Ohio 44135-3191 }\end{array}$} & $\begin{array}{l}\text { 8. PERFORMING ORGANIZATION } \\
\text { REPORT NUMBER } \\
\text { E-18277-1 }\end{array}$ \\
\hline \multirow{2}{*}{\multicolumn{5}{|c|}{$\begin{array}{l}\text { 9. SPONSORING/MONITORING AGENCY NAME(S) AND ADDRESS(ES) } \\
\text { National Aeronautics and Space Administration } \\
\text { Washington, DC 20546-0001 }\end{array}$}} & $\begin{array}{l}\text { 10. SPONSORING/MONITOR'S } \\
\text { ACRONYM(S) } \\
\text { NASA }\end{array}$ \\
\hline & & & & & $\begin{array}{l}\text { 11. SPONSORING/MONITORING } \\
\text { REPORT NUMBER } \\
\text { NASA/TM-2013-217821 }\end{array}$ \\
\hline \multicolumn{6}{|c|}{$\begin{array}{l}\text { 12. DISTRIBUTION/AVAILABILITY STATEMENT } \\
\text { Unclassified-Unlimited } \\
\text { Subject Categories: } 07 \text { and } 63 \\
\text { Available electronically at http://www.sti.nasa.gov } \\
\text { This publication is available from the NASA Center for AeroSpace Information, 443-757-5802 }\end{array}$} \\
\hline \multicolumn{6}{|c|}{$\begin{array}{l}\text { 13. SUPPLEMENTARY NOTES } \\
\text { Submitted to Journal of Aerospace Engineering, American Society of Civil Engineers (ASCE). }\end{array}$} \\
\hline \multicolumn{6}{|c|}{$\begin{array}{l}\text { 14. ABSTRACT } \\
\text { This paper provides an overview of the aircraft turbine engine control research at the NASA Glenn Research Center (GRC). A brief } \\
\text { introduction to the engine control problem is first provided with a description of the state-of-the-art control law structure. A historical aspect } \\
\text { of engine control development since the } 1940 \text { s is then provided with a special emphasis on the contributions of GRC. With the increased } \\
\text { emphasis on aircraft safety, enhanced performance, and affordability, as well as the need to reduce the environmental impact of aircraft, } \\
\text { there are many new challenges being faced by the designers of aircraft propulsion systems. The Controls and Dynamics Branch (CDB) at } \\
\text { GRC is leading and participating in various projects to develop advanced propulsion controls and diagnostics technologies that will help } \\
\text { meet the challenging goals of NASA Aeronautics Research Mission programs. The rest of the paper provides an overview of the various } \\
\text { CDB technology development activities in aircraft engine control and diagnostics, both current and some accomplished in the recent past. } \\
\text { The motivation for each of the research efforts, the research approach, technical challenges, and the key progress to date are summarized. }\end{array}$} \\
\hline \multicolumn{6}{|c|}{$\begin{array}{l}\text { 15. SUBJECT TERMS } \\
\text { Gas turbine engines; Engine control; Engine performance; Robust control; Fault detection }\end{array}$} \\
\hline \multicolumn{3}{|c|}{ 16. SECURITY CLASSIFICATION OF: } & $\begin{array}{l}\text { 17. LIMITATION OF } \\
\text { ABSTRACT }\end{array}$ & $\begin{array}{l}\text { 18. NUMBER } \\
\text { OF }\end{array}$ & $\begin{array}{l}\text { 19a. NAME OF RESPONSIBLE PERSON } \\
\text { STI Help Desk (email:help@sti.nasa.gov) }\end{array}$ \\
\hline $\begin{array}{l}\text { a. REPORT } \\
\text { U }\end{array}$ & $\begin{array}{l}\text { b. ABSTRACT } \\
\text { U }\end{array}$ & $\begin{array}{l}\text { c. THIS } \\
\text { PAGE } \\
\text { U }\end{array}$ & UU & $\begin{array}{l}\text { PAGES } \\
36\end{array}$ & $\begin{array}{l}\text { 19b. TELEPHONE NUMBER (include area code) } \\
443-757-5802\end{array}$ \\
\hline
\end{tabular}




